\title{
Sodium carbonate-based post combustion carbon capture utilising trona as main sorbent feed stock
}

\author{
Furcas, Fabio Enrico ${ }^{\mathrm{a}}$, Pragot, Wanawan ${ }^{\mathrm{a}}$, Chacartegui, Ricardo ${ }^{\mathrm{b}}$, Afzal, Waheed ${ }^{\mathrm{a}, *}$ \\ ${ }^{a}$ Chemical 83 Materials Engineering, School of Engineering, University of Aberdeen, Scotland, United \\ Kingdom \\ ${ }^{b}$ Escuela Técnica Superior De Ingeniería Sevilla, Universidad de Sevilla, Spain
}

\begin{abstract}
In the pursuit of shifting technology towards sustainable, environmentally benign processes, post-combustion carbon capture technology is recognised to be a timely mitigation option. This paper presents the development of a novel sodium carbonate-based post combustion carbon capture process utilising the carbonate mineral trona (trisodium hydrogendicarbonate dihydrate) as main sorbent feedstock source. The energy penalty, the fraction of energy sacrificed to capture $\mathrm{CO}_{2}$ relative to the net energy produced serves as main performance indicator. Investigations on the correlative relationship between energy penalty as a function of capture efficiency are carried out by retrofitting the process to a $600 M W$ reference coal-fired power plant. The energy penalty of the global system features a distinct local minimum of $3.99 \%$, corresponding to a $\mathrm{CO}_{2}$ capture efficiency of $90.00 \%$ and a $\mathrm{CO}_{2}$ outlet purity of $99.90 \%$. The Specific Primary Energy Consumption for $\mathrm{CO}_{2}$ Avoided (SPECCA) index corresponding to this minimum is evaluated to be SPECCA $=0.514 \mathrm{MJ} \mathrm{kg} \mathrm{CO}_{2}^{-1}$. Sensitivity analyses on the effect of increasingly high $\mathrm{SO}_{2}$ flue gas volume fractions $y_{\mathrm{SO}_{2}}$ show that the capture efficiency is virtually unimpaired for calcination temperatures of $190 \leq T \leq 280{ }^{\circ} \mathrm{C}$ and $y_{\mathrm{SO}_{2}}$ ranging from 0.50 to $0.70 \%$. Whilst commercially available $\mathrm{CO}_{2}$ capture technology is energy intense and prone to sorbent degradation, the process developed retains high capture efficiencies of calcium oxide-based looping cycles at low operating temperatures and eliminates the predisposition of amine-based sorbents utilised in scrubbing capture schemes to deplete due to the presence of $\mathrm{SO}_{2}$ in the inlet flue gas stream. It can be concluded that sodium carbonate based post-combustion capture processes are a competitive alternative to existing $\mathrm{CO}_{2}$ capture technologies.

Keywords: Carbon capture, Carbonate looping process, Trona, Sodium carbonate, Sodium bicarbonate,
\end{abstract}

\footnotetext{
${ }^{*}$ Corresponding author

Email addresses: fabio.furcas.14@aberdeen.ac.uk (Furcas, Fabio Enrico), r02wp17@abdn.ac.uk (Pragot, Wanawan), ricardoch@us.es (Chacartegui, Ricardo), waheed@abdn.ac.uk (Afzal, Waheed)
} 


\section{Introduction}

\subsection{Background}

The impact of anthropogenic greenhouse gas emissions on the environment is unprecedented. Cumulative release of these gasses is identified to be the largest contributor of the observed earth's surface temperature incline in the period from 1951 to 2010. With an approximated content of $76 \%$, carbon dioxide makes up the largest proportion of greenhouse gasses [1]. Carbon dioxide emissions in 2010 amount to an estimated 34 Gt per year [2], with this figure set to steadily increase. Human-induced emissions predominantly originate from a range of economic activities. These comprise the usage of non-renewable fossil fuels for energy generation, transportation and as industrial feedstock [3]. Limiting the pervasive intervention into the planets ecosystem caused by these activities is paramount to avert long-lasting and irreversible consequences for society and environment. Prognoses on continuously increasing population size, economic activity and therefore energy usage further stress the importance of technological advancement towards more sustainable, low-carbon processes.

During the past decades, carbon capture, utilization (CCU) and storage (CCS) has gained increasing levels of public attention [4]. This technique mitigates waste carbon dioxide emissions by either transforming $\mathrm{CO}_{2}$ into useful products or by depositing large quantities of the post-combustion gas underground. Whilst pilot-scale power plants making use of these novel concepts have already been implemented [5], the technology is still at an early developmental stage. Both capture and utilisation facilities are energy and emission intense in itself. Moreover, utilizing $\mathrm{CO}_{2}$ as an alternative carbon source implies that capture is not permanent. This limits the technology's scope and makes progress intrinsically challenging [3]. As a consequence, the desired technological shift towards increasingly more sustainable processes is compromised or even completely reversed, as the high energy requirement outweighs the immediate environmental benefit.

\subsection{Carbon capture technology}

Carbon capture requires energy. Retrofitting capture processes to existing power plants reduces the net energy output. In this context, it is of particular interest to investigate the processes energy penalty, i.e. the ratio of energy sacrificed to capture the $\mathrm{CO}_{2}$ relative to the net amount of energy produced. Currently developed carbon capture and storage technologies can be categorised based on the mechanism by which $\mathrm{CO}_{2}$ is removed from flue gas streams: Capture using (i) chemical or (ii) physical solvents, (iii) adsorption/desorption, (iv) membrane separation and (v) cryogenic separation $[3,6]$. Performance of these capture technologies is heavily dependant on flue gas stream temperature, $\mathrm{CO}_{2}$ partial pressure and the presence of $N O_{x}$ and $S O_{x}[7,8]$. As flue gas stream temperature and composition varies across industrial point sources, the suitability of capture technology utilised therefore depends on the stationary point source the process is retrofitted to. 
Utilising the principle of chemical absorption, amine scrubbing is the only immediately realisable capture technology to date. Bottoms [9] first successfully demonstrated the removal of acid gasses from natural gas streams, using a packed absorber column and a stripper assembled to form a solvent regeneration cycle. Amine scrubbing technology has proven to be feasible on pilot scale of coal- and gas-fired power plants with a range of companies offering commercial process packages [10]. Solvent blends of primary, tertiary and sterically hindered amines enable highly flexible processes, retaining fast reaction rates characteristic to primary amines whilst the capture capacity is simultaneously increased [11]. Despite existing commercial experience, there are two major concerns associated with this technology. Firstly, the energy intense solvent regeneration causes a drastic reduction in the overall power plant efficiency and results in high energy penalties of up to $12.5 \%$ [5, 12]. It has furthermore been demonstrated that amine scrubbing processes integrated with solar energy reduce the technologies emission intensity, with an overall efficiency increase of up to $1 \%$ [13], however, are ecologically unfavourable under consideration of the equipment cost [14]. Secondly, amine-based solvents degenerate over time by a number of mechanisms. $N O_{x}$ and $S O_{x}$ present in the flue gas stream can form stable salts with the amine species utilised. Furthermore, the presence of oxygen can lead to the formation of aldehydes and organic acids, attenuating the technologies environmental performance [11].

Carbonate looping schemes that capture $\mathrm{CO}_{2}$ via adsorption onto a sorbent and subsequently release that sorbent in arrangements of two or more interconnected fluidized bed reactors have been identified to be a promising alternative to currently available amine scrubbing technology [15]. Literature mainly proposes the utilisation of two different sorbents, calcium oxide $(\mathrm{CaO})$ and sodium carbonate $\left(\mathrm{Na}_{2} \mathrm{CO}_{3}\right)$. Reversible carbonation of calcium oxide according to

$$
\mathrm{CaO}_{(s)}+\mathrm{CO}_{2(g)} \rightleftharpoons \mathrm{CaCO}_{3(s)} \quad \Delta H^{\varnothing}=-178.0 \frac{\mathrm{kJ}}{\mathrm{mol}}
$$

can be utilised to capture $\mathrm{CO}_{2}$ from flue gas in a regenerative looping cycle. Whilst $\mathrm{CaO}$ carbonation proceeds at temperatures ranging from 625 to $680{ }^{\circ} \mathrm{C}$, sorbent regeneration (Equation 1 reversed) requires high calcination temperatures of 900 to 950 ${ }^{\circ} \mathrm{C}$ [16]. Availability of high grade heat allows for the calcium looping process to be integrated with the power plant upstream, making retrofit installations of the process less complex. Additionally, excess heat generated during the exothermic carbonation of $\mathrm{CaO}$ may be supplied to waste heat recovery units or used to power auxiliary process equipment directly [17]. It must furthermore be pointed out that calcium looping processes compare favourably to amine scrubbing technology, both as a stand-alone process and assisted by solar energy. Despite singular studies reporting an energy penalty of as low as $3 \%$ [18], values of most literature data available range from 6 to $8 \%[15,19]$. Romeo et al. [20] claim that carbonation/calcination looping systems are particularly advantageous compared to amine scrubbing schemes due to the "fact that no flue gases desulphurization unit is needed". This is in accordance with experiments carried out by [21], showing that reaction conversion rates in CaL cycles stabilise for a number of $\geq 20$ 
cycles despite the flue gas being $1 \mathrm{vol} . \%$ sulphated.

Similar sorption-desorption schemes based on the carbonation of sodium carbonate as shown in Equation 2 have been proposed [22].

$$
\mathrm{Na}_{2} \mathrm{CO}_{3(s)}+\mathrm{CO}_{2(g)}+\mathrm{H}_{2} \mathrm{O}_{(g)} \rightleftharpoons 2 \mathrm{NaHCO}_{3(s)} \quad \Delta H^{\varnothing}=-129.1 \frac{\mathrm{kJ}}{\mathrm{mol}}
$$

In a process analogous to its calcium-based counterpart, $\mathrm{CO}_{2}$ can be captured from flue gas via an arrangement of 4 interconnected fluidised bed reactors where the carbonate mineral trona is used as main sorbent feed stock. Similar to the assisted sorbent regeneration schemes presented in [14], the energy required for $\mathrm{Na}_{2} \mathrm{CO}_{3}$ calcination in the respective calciner and regenerator units $\left(\dot{Q}_{H}\right)$ is provided by solar energy. Figure 1 illustrates this arrangement in the form of a schematic block diagram, where all separation stages have been omitted.

Hanak et al. [19] highlight the substantial potential of carbonate looping schemes to improve on currently reported energy penalty values utilising alternative process configurations and sorbents. Similarly, it is pointed out that the competitive performance of novel carbon capture technology must be assessed both from an ecological and thermodynamic viewpoint. With previous work [22] focusing on the cost analysis of the capture scheme proposed, an investigation of the energy penalty associated with the usage of sodium carbonate looping cycles has not been carried out to date. In this context, this paper explores the potential to further improve the technology's performance on utilising $\mathrm{Na}_{2} \mathrm{CO}_{3} / \mathrm{NaHCO}_{3}$ as an alternative to well-studied calcium-based looping cycles. Design objectives pursued in this manuscript are to investigate the selectivity of $\mathrm{Na}_{2} \mathrm{CO}_{3}$ carbonation compared to undesired side reactions resulting in the irreversible depletion of sodium carbonate. Optimal operating temperatures of all reactive systems involved are determined. Computational results generated by industrial-standard software are validated by a thermodynamic model based on the principle of Gibbs free energy minimisation. Lastly, a correlative relationship of the overall energy penalty as a function of $\mathrm{CO}_{2}$ capture efficiency is established.

\section{Model Development}

In the chemical and engineering industry today, the business practise of supply chain planning is of utmost importance to satisfy shifting marked demands. Adversity to making large investments into existing manufacturing facilities and the objective to generate shareholder value causes most companies to review the way their assets are managed [23]. To combat demand uncertainty, flexible processes that can adapt to these changes are desirable. The integrated capture cycle presented in this section can be run in several configurations that vary the amount of $\mathrm{CO}_{2}$ fixated according sorbent availability and flue gas composition. As previously elucidated, this section provides a detailed description of the objectives pursued by modelling these configurations. 


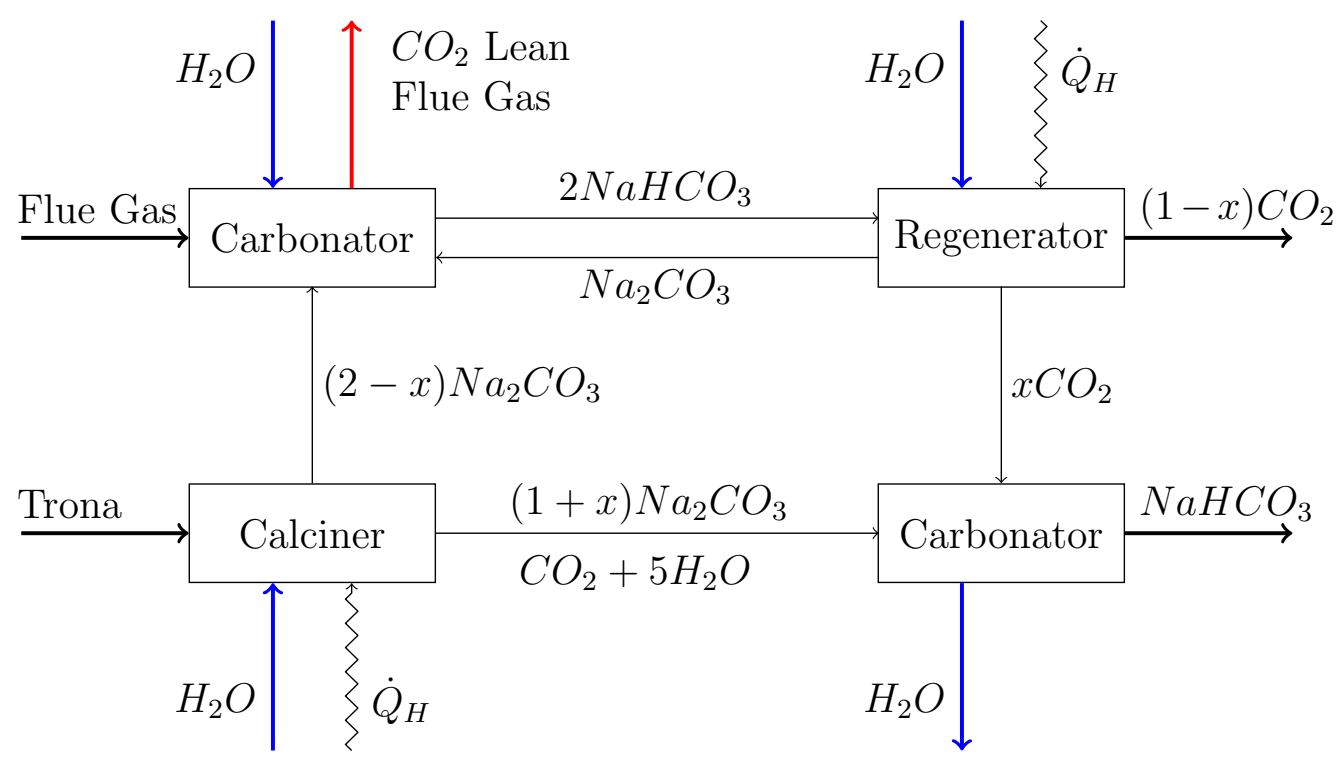

Figure 1: Schematic block diagram of an integrated carbonate $\mathrm{CO}_{2}$ sequestration process utilizing trona as a sorbent feedstock.

\subsection{Methodology}

Initially, a base-case process modelling the the extend of $\mathrm{CO}_{2}$ capture in the proposed $\mathrm{Na}_{2} \mathrm{CO}_{3}$ based looping scheme is developed. Trona decomposition extents are determined utilising computational data on the respective component's thermochemistry. For this base-case, it is assumed that $\mathrm{Na}_{2} \mathrm{CO}_{3}$ does not degrade due to the presence of $\mathrm{SO}_{2}$ in the inlet flue gas stream. Subsequent to the initial stage of process design, base-case assumptions made are lifted, allowing for $\mathrm{Na}_{2} \mathrm{CO}_{3}$ to undergo irreversible depletion due to $\mathrm{SO}_{2}$ present in the inlet flue gas stream. Previously determined base-case operating conditions serve as a foundation to to optimise process operating parameters. In detail, the optimisation carried out considers changes in reactor unit temperature, sorbent to $\mathrm{CO}_{2}$ ratio, percentage flue gas $\mathrm{SO}_{2}$ content and make-up flow. As the individual process parameters affect each other reciprocally, the combined influence on overall system performance is investigated via an iterative optimisation approach. Relevant conclusions between the changes in energy penalty with varying capture efficiency compared base-case results are drawn.

Mass and energy balances corresponding to each process configuration modelled are solved using Aspen Plus V9. To rigorously model the phase behaviour of carbonate species in liquid phase of reactor R101, Electrolyte-NRTL is respective fluids package chosen. Additionally, the package SOLIDS is assigned to all solid sub streams. It is assumed that the employed Aspen Plus reactor units and separation stages describe the system's thermodynamic behaviour sufficiently well. In detail, the model presented in this section is based on the following assumptions:

- Complete separation of the respective solid and gas outlet streams of units S101 and S102. 
- All reactors and heat exchangers used have a pressure drop of $\Delta P=0.5$ bar and can be perfectly heat integrated.

- The isentropic pump and compressor efficiencies are taken to be $\eta=0.75$.

- The process operates at steady-state.

- The extent of reactions taking place within all reactors is accurately predicted by the chemical and phase equilibrium computations of the reactor sizing model RGIBBS.

To verify the latter assumption, a two-phase, multiple reaction thermodynamic model based on the principle of Gibbs free energy minimisation has been implemented independent of the ASPEN simulation. For all simulations carried out, inlet flue gas stream flow rate and composition are fixed to reference plant data collected by [18] and summarised in Table 1. Tables 2 and 3 display the corresponding final process equipment list along with a process flow diagram and stream table. 
Table 1: Main operating conditions and flue gas composition of the reference coal-fired power plant plant considered [18].

\begin{tabular}{ll}
\hline \hline Gross Power Output & $600.0 \mathrm{MW}$ \\
Flue Gas Mass Flow Rate & $647.6 \mathrm{~kg} \mathrm{~s}^{-1}$ \\
Flue Gas Temperature & $423.0 \mathrm{~K}$ \\
\hline Flue Gas Composition by vol. \% & \\
$\mathrm{CO}_{2}$ & 12.0 \\
$\mathrm{~N}_{2}$ & 73.7 \\
$\mathrm{H}_{2} \mathrm{O}$ & 8.30 \\
$\mathrm{O}_{2}$ & 5.50 \\
$\mathrm{SO}_{2}$ & 0.50 \\
\hline \hline
\end{tabular}

Table 2: Integrated sodium carbonate-based looping cycle developed in this work - process equipment list. Refer to Table 3 for the process equipment nomenclature

\begin{tabular}{llll}
\hline \hline Equipment & Description & Parameter & Value \\
\hline C101 & Inlet flue gas compressor & Duty (Work) & $165.45 \mathrm{MW}$ \\
E101 & Mixed recycling stream cooler & Duty (Cooling) & $167.89 \mathrm{MW}$ \\
E102 & S102 inlet cooler & Duty (Cooling) & $112.90 \mathrm{MW}$ \\
E103 & S101 tops products cooler & Duty (Cooling) & $110.14 \mathrm{MW}$ \\
E104 & Outlet CO ${ }_{2}$ water condenser & Duty (Cooling) & $137.60 \mathrm{MW}$ \\
E105 & R103 inlet heater & Duty (Heating) & $120.14 \mathrm{MW}$ \\
P101 & Mixed recycling stream pump & Duty (Work) & $0.7001 \mathrm{MW}$ \\
P102 & Trona brine feed pump & Duty (Work) & $0.0177 \mathrm{MW}$ \\
R101 & Carbonator reactor unit & Duty (Cooling) & $500.00 \mathrm{MW}$ \\
R102 & Calciner reactor unit & Duty (Heating) & $500.00 \mathrm{MW}$ \\
R103 & Calciner reactor unit & Duty (Heating) & $45.214 \mathrm{MW}$ \\
S101 & R101 products solid-gas separator & Duty (Heating) & $174.35 \mathrm{MW}$ \\
S102 & R102 products solid-gas separator & Duty (Cooling) & $47.261 \mathrm{MW}$ \\
\hline
\end{tabular}

Simulator: Aspen Plus V 9.2 with Electorlyte NRTL for fluid phases, SOLIDS for solid substreams, and RGIBBS for equilibrium reactors. 
Table 3: Integrated sodium carbonate-based looping cycle - process flow diagram and stream table.

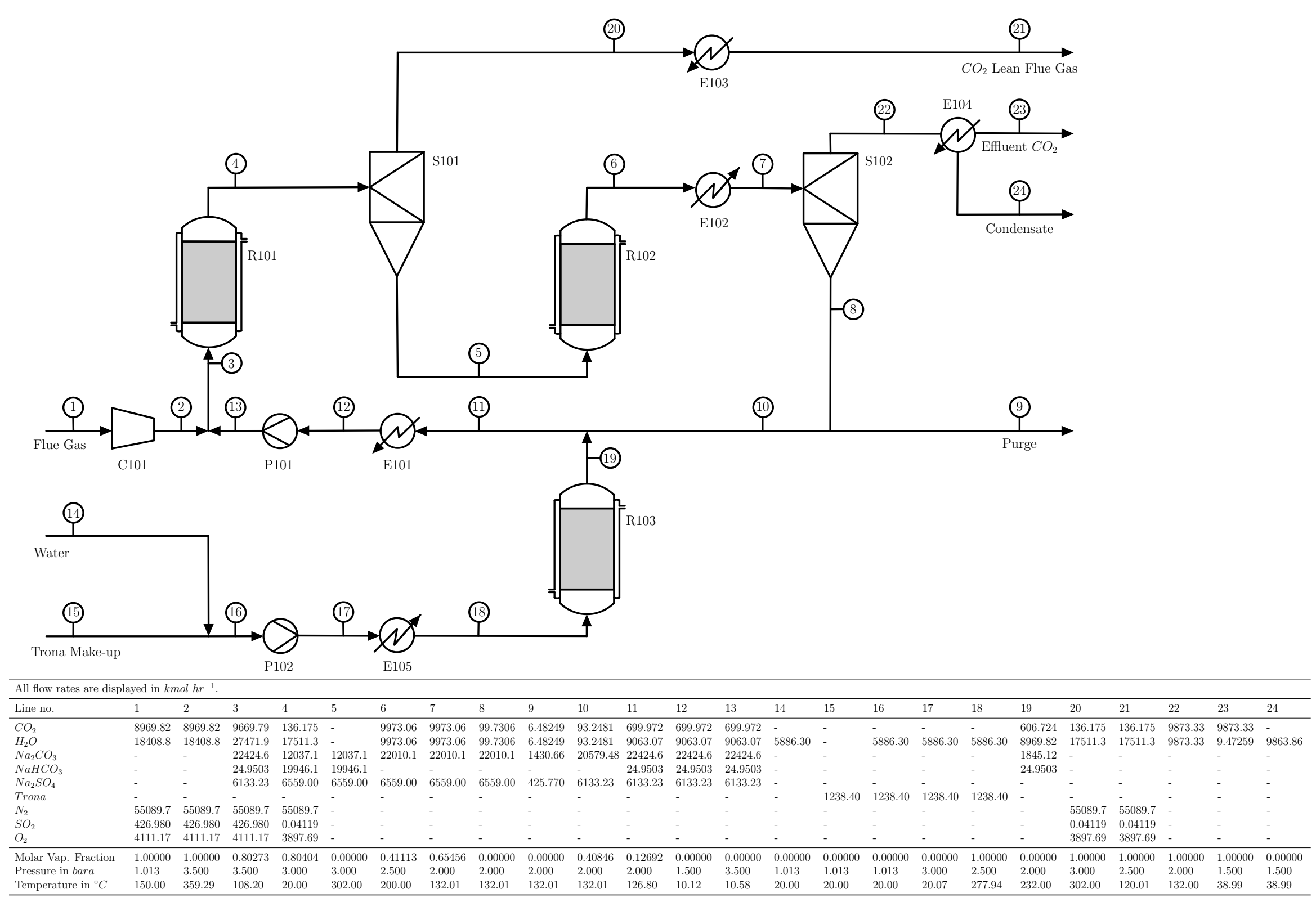




\subsection{Thermochemistry of Trona Brines}

The carbonate mineral trisodium hydrogendicarbonate dihydrate $\left(\mathrm{Na}_{2} \mathrm{CO}_{3} \cdot \mathrm{NaHCO}_{3}\right.$. $2 \mathrm{H}_{2} \mathrm{O}$ ), hereafter referred to as trona, decomposes at temperatures $>160{ }^{\circ} \mathrm{C}$ according to Equation 3 [24].

$$
2(\mathrm{Na} 2 \mathrm{CO} 3 \cdot \mathrm{NaHCO} \cdot 2 \mathrm{H} 2 \mathrm{O})_{(s)} \rightarrow 3 \mathrm{Na}_{2} \mathrm{CO}_{3(s)}+\mathrm{CO}_{2(g)}+5 \mathrm{H}_{2} \mathrm{O}_{(v)}
$$

Trona decomposition hence yields 1.5 equivalents of $\mathrm{Na}_{2} \mathrm{CO}_{3}$ and 2.5 equivalents of $\mathrm{H}_{2} \mathrm{O}$, both of which are reactants required to capture $\mathrm{CO}_{2}$ from flue gas via $\mathrm{Na}_{2} \mathrm{CO}_{3}$ carbonation. This section investigates the extend of trona decomposition as a function of temperature. Optimal R103 calciner operating temperatures dictating the $\mathrm{Na}_{2} \mathrm{CO}_{3}$ make-up stream purity are derived from this analysis. Sediment deposits of trona are found in a range of countries including the United States of America, Turkey and China [25], [26] and [27]. Table 4 presents it's corresponding mass composition in percentage:

Table 4: Natural trona composition by mass percentage [22].

\begin{tabular}{lrrrrrr}
\hline Component & $\mathrm{Na}_{2} \mathrm{CO}_{3}$ & $\mathrm{NaHCO}_{3}$ & $\mathrm{Na}_{2} \mathrm{SO}_{4}$ & Insolubles & $\mathrm{H}_{2} \mathrm{O}$ & Others \\
Mass \% & 46.53 & 34.82 & 0.568 & 2.980 & 14.92 & 0.182 \\
\hline
\end{tabular}

The vapour liquid equilibrium of the respective carbonator process blocks is complex due to the present of ionic species in aqueous phase. Trona decomposition and the carbonation of sodium bicarbonate is associated with a range of equilibrium reactions and can lead to the formation of unwanted mono- and ployhydrate salts [22]. The sequence of $\mathrm{Na}_{2} \mathrm{CO}_{3}$ carbonation to form $\mathrm{NaHCO}_{3}$ is described by:

$$
\begin{aligned}
& \mathrm{CO}_{2}+2 \mathrm{H}_{2} \mathrm{O} \rightleftharpoons \mathrm{H}_{3} \mathrm{O}^{+}+\mathrm{HCO}_{3}^{-} \\
& \mathrm{HCO}_{3}^{-}+\mathrm{H}_{2} \mathrm{O} \rightleftharpoons \mathrm{H}_{3} \mathrm{O}^{+}+\mathrm{CO}_{3}^{-2} \\
& \mathrm{NaHCO}_{3} \rightleftharpoons \mathrm{Na}^{+}+\mathrm{HCO}_{3}^{-} \\
& \mathrm{Na}_{2} \mathrm{CO}_{3} \rightleftharpoons 2 \mathrm{Na}^{+}+\mathrm{CO}_{3}^{-2}
\end{aligned}
$$

Additionally, sodium bicarbonate may form mono- hepta- and decahydrate salts with the corresponding stoichiometric amount of water as presented in Equations 8 to 10.

$$
\begin{aligned}
& \mathrm{Na}_{2} \mathrm{CO}_{3} \cdot \mathrm{H}_{2} \mathrm{O} \rightleftharpoons 2 \mathrm{Na}^{+}+\mathrm{CO}_{3}^{-2}+\mathrm{H}_{2} \mathrm{O} \\
& \mathrm{Na}_{2} \mathrm{CO}_{3} \cdot 7 \mathrm{H}_{2} \mathrm{O} \rightleftharpoons 2 \mathrm{Na}^{+}+\mathrm{CO}_{3}^{-2}+7 \mathrm{H}_{2} \mathrm{O} \\
& \mathrm{Na}_{2} \mathrm{CO}_{3} \cdot 10 \mathrm{H}_{2} \mathrm{O} \rightleftharpoons 2 \mathrm{Na}^{+}+\mathrm{CO}_{3}^{-2}+10 \mathrm{H}_{2} \mathrm{O}
\end{aligned}
$$

Lastly, the formation and dissociation of Wegscheider's salt and trona has to be considered:

$$
\begin{aligned}
& \mathrm{Na}_{2} \mathrm{CO}_{3} \cdot 3 \mathrm{NaHCO}_{3} \rightleftharpoons 5 \mathrm{Na}^{+}+\mathrm{CO}_{3}^{-2}+3 \mathrm{HCO}_{3}^{-} \\
& \mathrm{Na}_{2} \mathrm{CO}_{3} \cdot \mathrm{NaHCO}_{3} \cdot 2 \mathrm{H}_{2} \mathrm{O} \rightleftharpoons 3 \mathrm{Na}^{+}+\mathrm{CO}_{3}^{-2}+\mathrm{HCO}_{3}^{-}+2 \mathrm{H}_{2} \mathrm{O}
\end{aligned}
$$


To find the optimal calciner operating temperature, the equilibrium constants of all possible reactions involved must be evaluated. According to thermochemical analysis of Trona brines by [28] utilising Pitzer's activity coefficient model, the equilibrium constants of above reactions as a function of temperature $K_{i}=f(T)$ can be approximated by

$$
\ln \left(K_{i}\right)=A_{i}+\frac{B_{i}}{T}+C_{i} \ln (T)+D_{i} T
$$

where $\{A, B, C, D\}_{i}$ are reaction specific constants of the equations $6-12$ and $\mathrm{T}$ is in the units of ${ }^{\circ} C$. The progression of $\ln \left(K_{i}\right)=f(T)$ for various reactions involved is visualised in Figure 2.

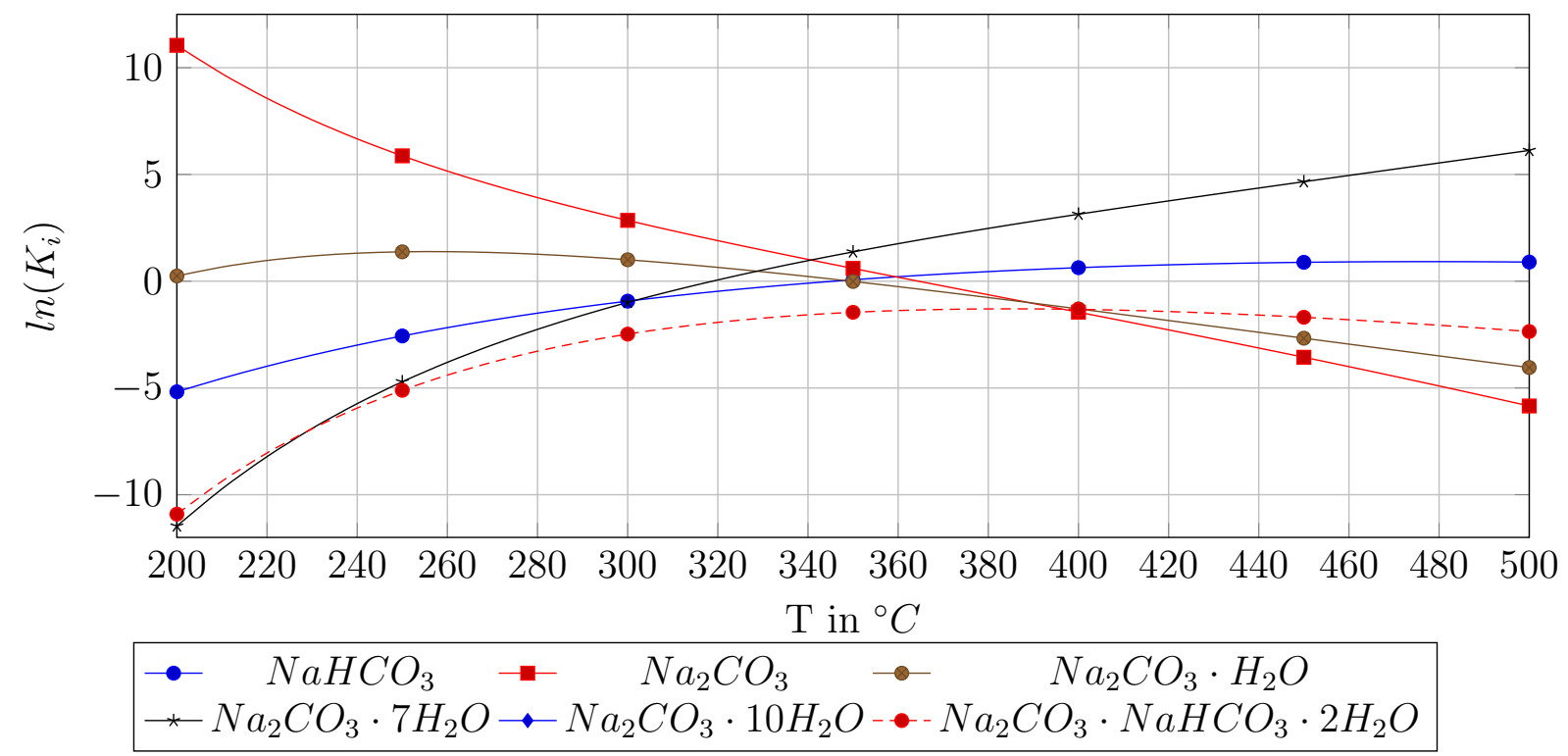

Figure 2: $\ln \left(K_{i}\right)$ for the equilibrium dissociation reactions of various carbonate and salt compounds as a function of temperature from 200 to $500{ }^{\circ} \mathrm{C}$.

By defining the respective equilibrium constants as dissociation constants, i.e. considering the left hand side as reactants decomposing into their ionic constituents, reactant and product concentration of each unit can be expressed as a ratio of temperature dependant equilibrium constants. The desired operating conditions for the calcination of trona correspond to the temperature at which the equilibrium of reaction 12 is product favoured. By a series of rearrangements it can be shown that the equilibrium constant $K_{9}$ can be written as:

$$
K_{9}=\frac{\left[\mathrm{Na}^{+}\right]^{3}\left[\mathrm{CO}_{3}^{-2}\right]\left[\mathrm{HCO}_{3}^{-}\right]\left[\mathrm{H}_{2} \mathrm{O}\right]^{2}}{\left[\mathrm{Na}_{2} \mathrm{CO}_{3} \cdot \mathrm{NaHCO}_{3} \cdot 2 \mathrm{H}_{2} \mathrm{O}\right]}=K_{3} K_{4} \frac{\left[\mathrm{NaHCO}_{3}\right]\left[\mathrm{Na}_{2} \mathrm{CO}_{3}\right]\left[\mathrm{H}_{2} \mathrm{O}\right]^{2}}{\left[\mathrm{Na}_{2} \mathrm{CO}_{3} \cdot \mathrm{NaHCO}_{3} \cdot 2 \mathrm{H}_{2} \mathrm{O}\right]}
$$

It is evident that trona decomposition is promoted by minimizing the ratio of $K_{3}(T) K_{4}(T)$ to $K_{9}(T)$. The progression of decomposition is illustrated in Figure 3.

It can be recognised that the mole fraction of trona strictly and monotonically decreases for $T \rightarrow \infty$. To find the calciner unit operating point, a trade-off between extent 


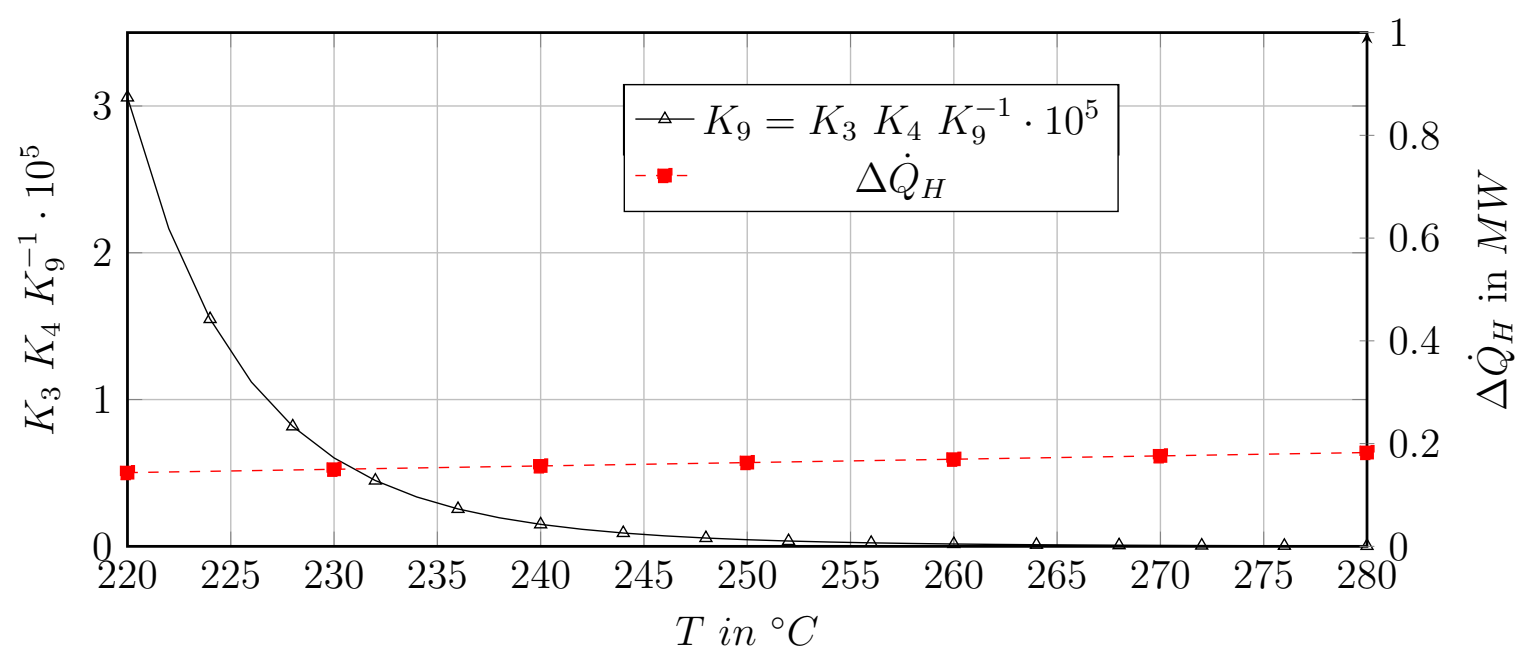

Figure 3: Ratio of $K_{9}(T)$ for the decomposition of trona and reactor heating duty $\Delta \dot{Q}_{H}$ in $M W$ as a function of temperature from 220 to $280^{\circ} \mathrm{C}$.

of decomposition and reactor heating duty has to be considered. A sensitivity analysis investigating the effect of changes in operating temperature on $\Delta \dot{Q}_{H}$ shows that reactor duty linearly increases with temperature on the interval considered. It is assumed that the intersect of both graphs at $T=232{ }^{\circ} \mathrm{C}$ represents the optimal trade-off between extend of decomposition and heating duty increment. At this temperature, the amount of undecomposed trona present in the reactor is negligible and the reaction can be considered as completely shifted to the product side. This is in accordance with existing literature suggesting an operating temperature range of $200-240{ }^{\circ} \mathrm{C}$ [22]. 


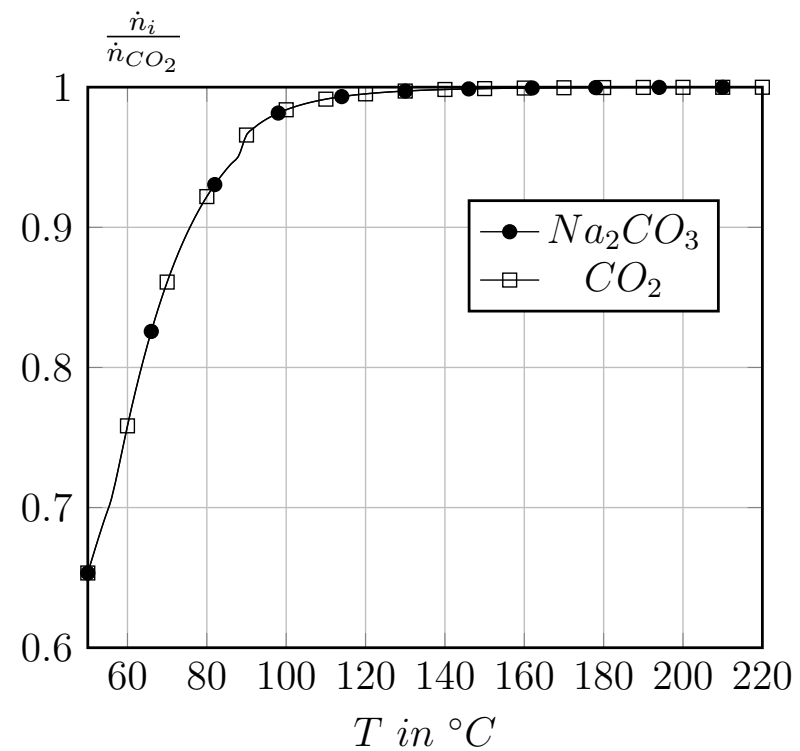

\subsection{Base-Case}

The $\mathrm{CO}_{2}$ capture capacity of the process developed is controlled by varying the amount of $\mathrm{Na}_{2} \mathrm{CO}_{3}$ available for carbonation. It has been shown that capture rates of analogous calcium-based looping cycles are heavily dependant on sorbent to $\mathrm{CO}_{2}$ ratio and consequently on the extent of sorbent depletion [29]. For the base-case simulation subject of this section, it is assumed $\mathrm{Na}_{2} \mathrm{CO}_{3}$ does not deplete. Furthermore, sorbent to $\mathrm{CO}_{2}$ ratios are restricted to a maximum of $\dot{n}_{\mathrm{Na}_{2} \mathrm{CO}_{3}} \dot{n}_{\mathrm{CO}_{2}}^{-1}=1$ and additional trona supply is not needed. The resultant looping cycle is presented in Figure 4.

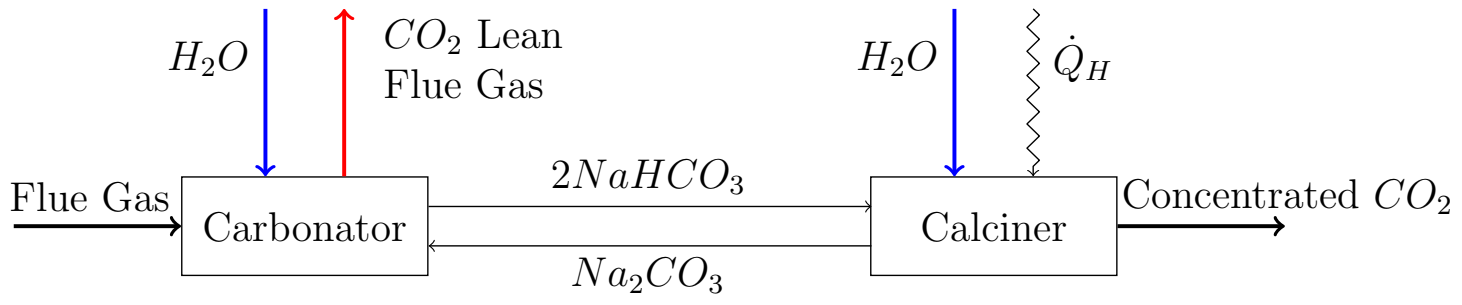

Figure 4: Block diagram of a sodium carbonate-based $\mathrm{CO}_{2}$ looping cycle.

Key characteristics of this scenario are to utilise the exothermicity of $\mathrm{Na}_{2} \mathrm{CO}_{3}$ carbonation to provide energy for the consecutive endothermic solvent regeneration. Car-

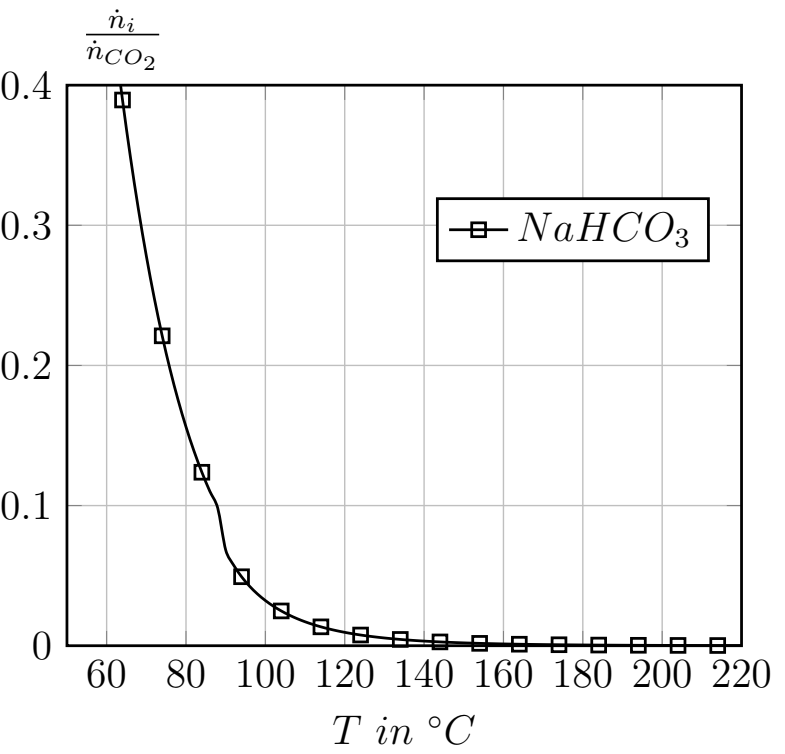

Figure 5: Equilibrium reactor (RGIBBS) calciner outlet flow rates $\dot{n}_{i}$ relative to a total inlet $\mathrm{CO}_{2}$ flow rate of $\dot{n}_{\mathrm{CO}_{2}}=8250 \mathrm{kmol} \mathrm{hr} r^{-1}$ at $P=1 \mathrm{~atm}$ on the interval of $\mathrm{T}$ between 50 to $220^{\circ} \mathrm{C}$.

bonator and calciner units are modelled as Aspen Plus RGIBBS reactor blocks, where the respective carbonation and calcination reaction extents vary with operating temperature $\xi_{R}=f(T)$. Optimal calciner operating conditions of the base-case considered are investigated using a sensitivity analysis tabulating the extent of sorbent regeneration 
on the temperature interval from 50 to $220^{\circ} \mathrm{C}$. Figure 5 visualises the corresponding outlet flow rates relative to the total inlet $\mathrm{CO}_{2}$ flow rate. Note, the flow rate profiles of $\mathrm{CO}_{2}$ and $\mathrm{Na}_{2} \mathrm{CO}_{3}$ are concurrent. It can be recognised that the incoming $\dot{n}_{\mathrm{NaHCO}_{3}}$ is consumed as both $\dot{n}_{\mathrm{CO}_{2}}$ and $\dot{n}_{\mathrm{Na}_{2} \mathrm{CO}_{3}}$ approach the amount of $\mathrm{Na}_{2} \mathrm{CO}_{3}$ initially fed into the system. For $T=210{ }^{\circ} \mathrm{C}$, the amount of $\mathrm{CO}_{2}$ released is greater than $0.9999 \dot{n}_{\mathrm{CO}_{2}}$ and the reaction has virtually run to completion. Conversely, $\mathrm{Na}_{2} \mathrm{CO}_{3}$ carbonation is promoted up to the same fractional conversion at a temperature of $T=29^{\circ} \mathrm{C}$.

\subsection{Sorbent Degradation}

Incorporating the phenomenon of sorbent depletion into the carbonate looping model significantly impacts the choice of process operating conditions. To re-evaluate these conditions, a variety of factors must be considered. The key objective pursued is to maximise the processes $\mathrm{CO}_{2}$ capture efficiency and simultaneously to retain low energy penalties of the base-case developed. Allowing the $\mathrm{Na}_{2} \mathrm{CO}_{3}$ sorbent utilised in the process to deplete due to sulphurous species present in the inlet flue gas stream, a range of additional reactions must be accounted for. Over a series of elementary steps outlined in [22] and [30], absorption of gaseous $\mathrm{SO}_{x}$ into aqueous $\mathrm{Na}_{2} \mathrm{CO}_{3} / \mathrm{NaHCO}_{3}$ solution results in the formation of sulphurous and sulphuric acid. As reference power plant flue gas composition data available only tabulates $\mathrm{SO}_{2}$ volume fractions, it will be assumed that the reaction of $\mathrm{Na}_{2} \mathrm{CO}_{3}$ and $\mathrm{SO}_{2}$ under the presence of oxygen according to

$$
\mathrm{Na}_{2} \mathrm{CO}_{3}(a q)+\mathrm{SO}_{2}(g)+\frac{1}{2} \mathrm{O}_{2}(g) \rightleftharpoons \mathrm{Na}_{2} \mathrm{SO}_{4}(a q)+\mathrm{CO}_{2}(g)
$$

representatively describes the phenomenon of sorbent depletion.

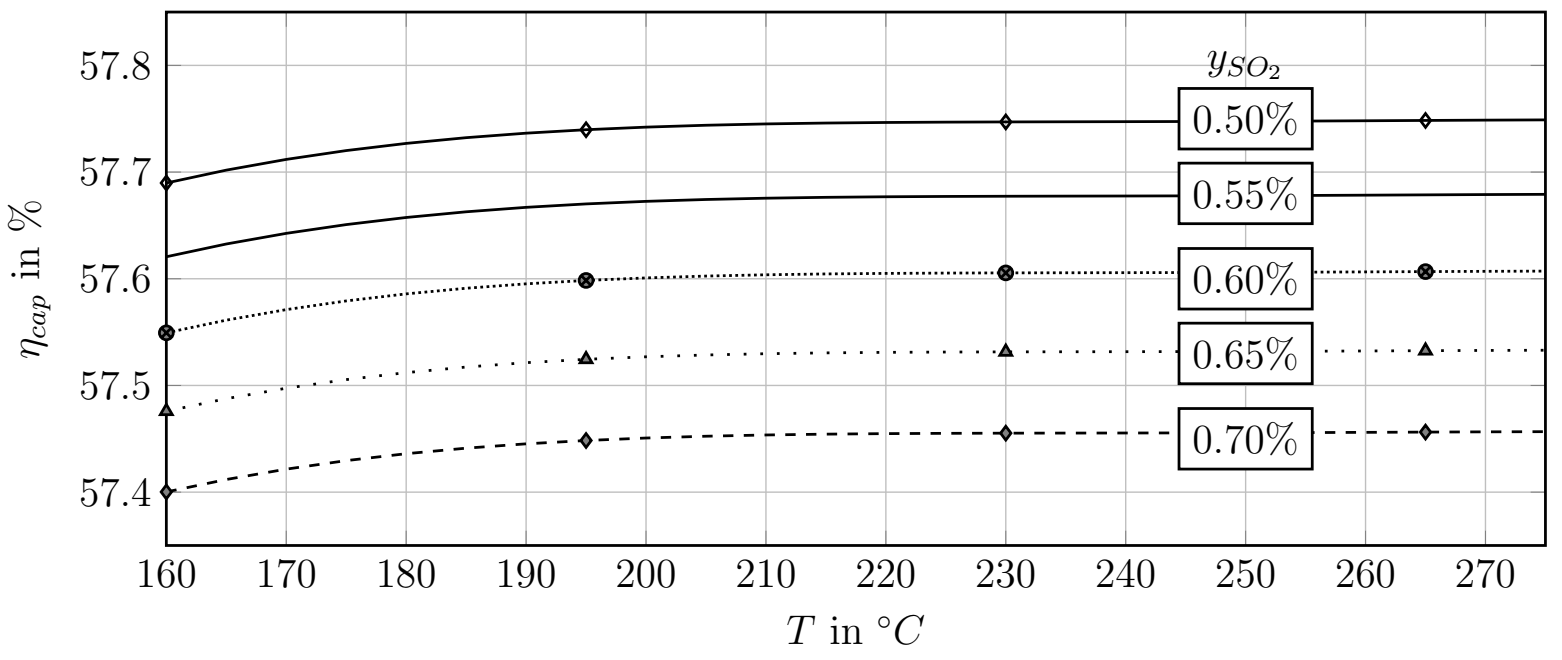

Figure 6: Process capture efficiencies $\eta_{\text {capt }}$ for various inlet flue gas $\mathrm{SO}_{2}$ volume fractions $y_{\mathrm{SO}_{2}}$ varying from 0.50 to $0.70 \%$ as a function of R102 operating temperature on the interval $160 \leq T_{R 102} \leq 280$ ${ }^{\circ} \mathrm{C}$.

The limiting factor determining $\mathrm{CO}_{2}$ capture efficiency are the respective effluent 
flow rates in R102. The extend of sorbent regeneration and conversely the amount of $\mathrm{CO}_{2}$ released relative to the process inlet vary with unit temperature $T_{R 102}$ and total amount of $\mathrm{Na}_{2} \mathrm{CO}_{3}$ available for carbonation. As the $\mathrm{SO}_{2}$ content in the inlet flue gas stream effectively reduces the amount of sorbent available, both changes in temperature and flue gas $\mathrm{SO}_{2}$ content must be considered to determine the optimal unit operating conditions. Figure 6 visualises the change in $\mathrm{CO}_{2}$ capture efficiency for a sorbent to $\mathrm{CO}_{2}$ ratio of 1 on a unit temperature interval of $160 \leq T_{R 102} \leq 280{ }^{\circ} \mathrm{C}$ and various sulphur dioxide contents. It can be recognised that $\eta_{c a p}$ is constant for operating temperatures $T_{R 102} \geq 200{ }^{\circ} \mathrm{C}$ and stable across the range of inlet $\mathrm{SO}_{2}$ volume fractions considered. Variations in capture efficiency for $y_{\mathrm{SO}_{2}} \geq 0.50 \%$ are due the increasing extend of sorbent depletion according to Equation 15. For any given $y_{\mathrm{SO}_{2}}$, a trade-off between $\mathrm{CO}_{2}$ release rate and therefore $\eta_{c a p}$ and the contribution of the reactor duty to the overall process energy penalty must be considered.

\subsection{Final Process}

To find the most prolific set of operating conditions, it is imperative to account for the interrelation between changes in one of the above parameters and consequentially arising changes for the remaining ones. Investigations of this reciprocal influence were assessed via an iterative approach, based on the previously determined base-case optimum.

For operating temperatures of $T_{R 101}<80{ }^{\circ} \mathrm{C}$ [31], $\mathrm{Na}_{2} \mathrm{CO}_{3}$ carbonation is found to be feasible and the resultant $\mathrm{NaHCO}_{3}$ produced stable, with conversion rates monotonically decreasing as this upper temperature limit is approached. In contrast, the extent of sorbent degradation according to Equation 15 increases. Figure 7 visualises this trend for a sorbent to $\mathrm{CO}_{2}$ ratio of $\dot{n}_{\mathrm{Na}_{2} \mathrm{CO}_{3}} \dot{n}_{\mathrm{CO}_{2}}^{-1}=2$.

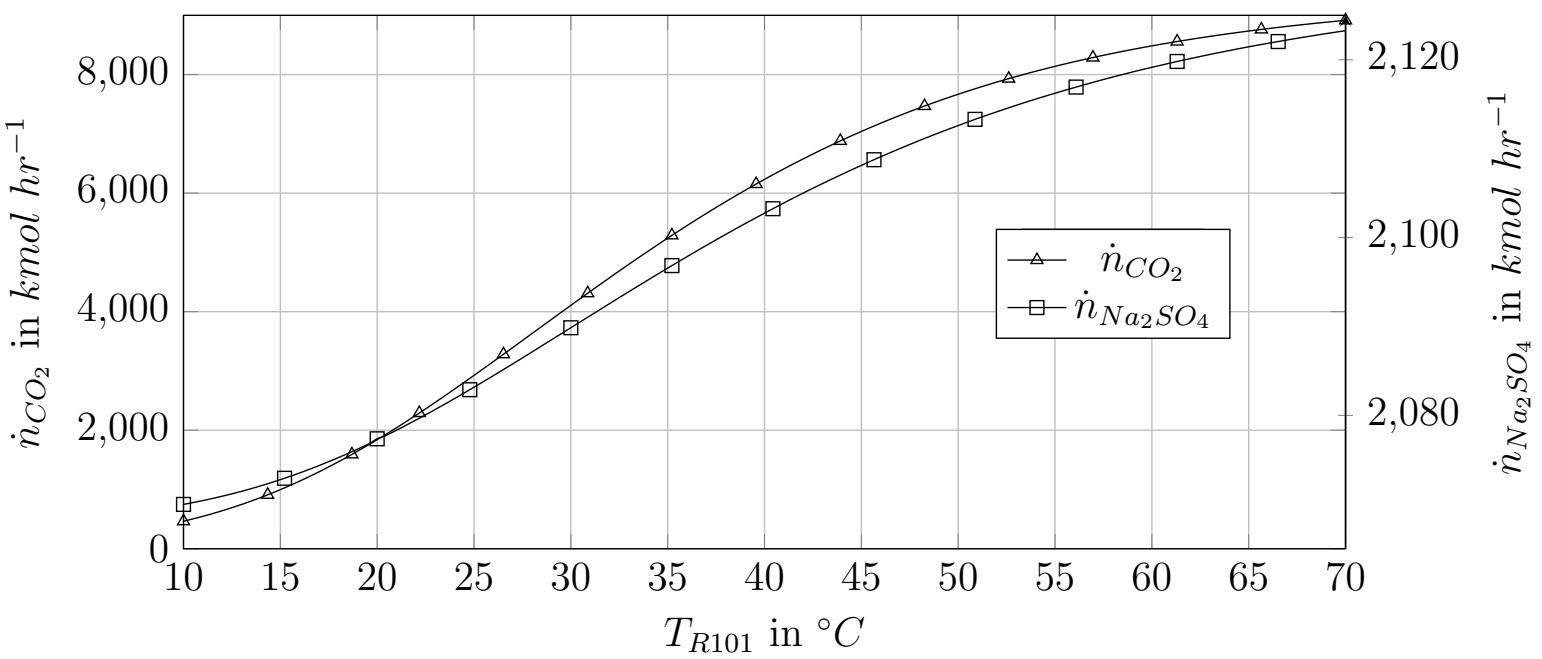

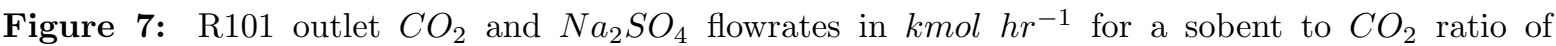
$\dot{n}_{\mathrm{Na}_{2} \mathrm{CO}_{3}} \dot{n}_{\mathrm{CO}_{2}}^{-1}=2$ on the R101 operating temperature range of $10<T_{R 101}<70{ }^{\circ} \mathrm{C}$.

As it is desirable to to minimise both the unreacted $\mathrm{CO}_{2}$ and $\mathrm{Na}_{2} \mathrm{SO}_{4}$ contained in the effluent reactor stream, the R101 design temperature must be kept as low as possibly feasible. Continuous refinement of the R101 and R102 operating temperatures 


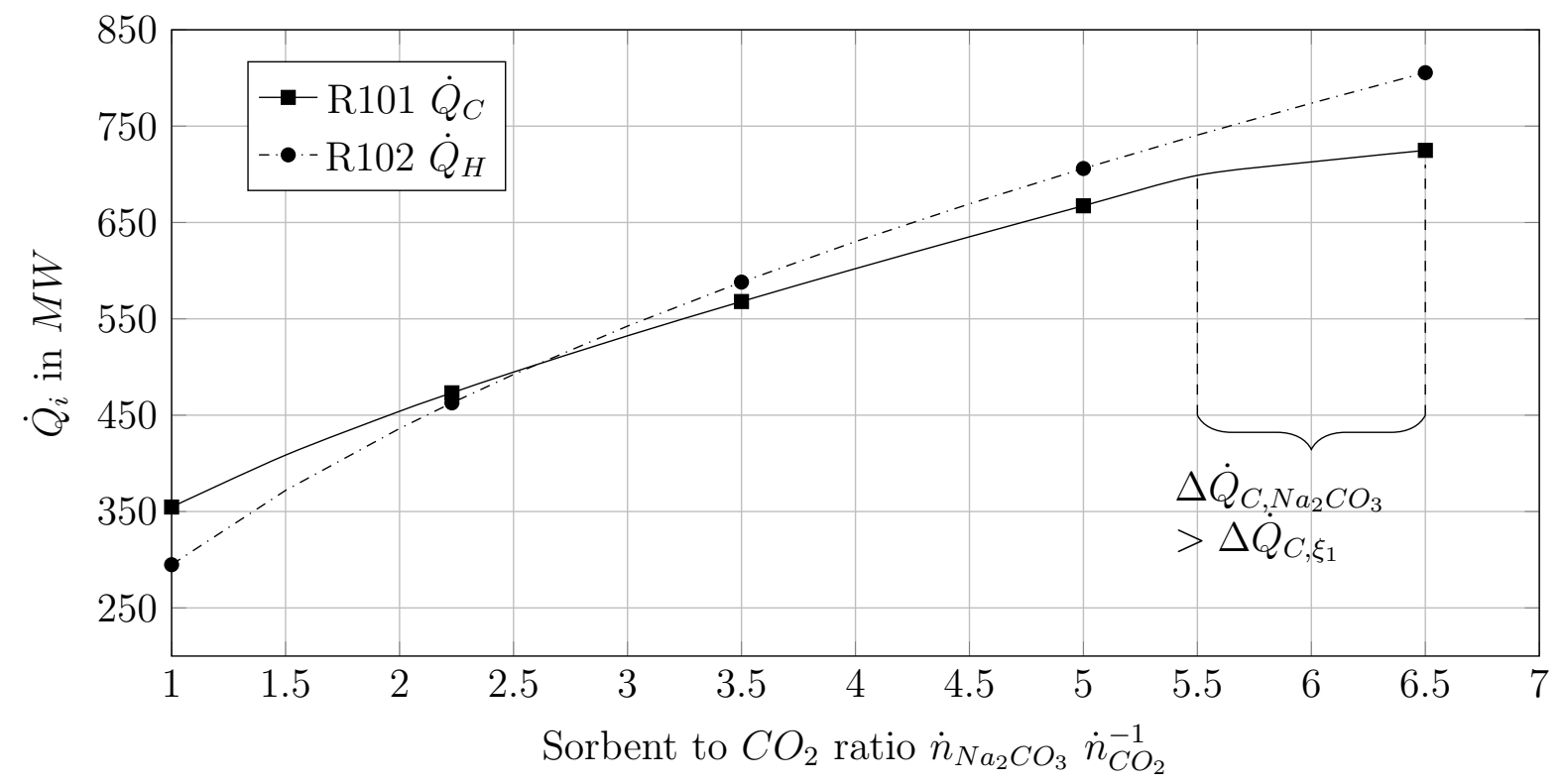

Figure 8: R101 and R102 cooling and heating duties $\dot{Q}_{C}$ and $\dot{Q}_{H}$ in $M W$ as a function of sorbent to $\mathrm{CO}_{2}$ ratio ranging from 1 to 7 at operating temperatures of $T_{R 101}=20{ }^{\circ} \mathrm{C}$ and $T_{R 102}=200{ }^{\circ} \mathrm{C}$.

via the iterative approach utilised has shown that the lowest energy penalty corresponds to $T_{R 101}=20{ }^{\circ} \mathrm{C}$ and $T_{R 102}=200{ }^{\circ} \mathrm{C}$. This set of operating temperatures facilitates $\mathrm{Na}_{2} \mathrm{CO}_{3}$ carbonation and subsequent sorbent regeneration resulting in the maximum $\mathrm{CO}_{2}$ capture efficiency achievable at any given flue gas $\mathrm{SO}_{2}$ volume fraction.

Investigating the extent of $\mathrm{Na}_{2} \mathrm{CO}_{3}$ carbonation and sorbent regeneration as a function of sorbent to $\mathrm{CO}_{2}$ ratio shows that $\mathrm{CO}_{2}$ capture efficiency improves significantly for excess $\mathrm{Na}_{2} \mathrm{CO}_{3}$ present in the system. This improvement in conversion rates for excess sorbent present in the looping cycle is in accordance with experimental results of analogous carbonate-based capture processes [32]. To determine the optimal excess rate of sorbent present in the system, a trade-off between $\mathrm{CO}_{2}$ capture and release rates and energy penalty must be considered. Variations in the respective reactor duties for the revised optimal operating temperatures of $T_{R 101}=20{ }^{\circ} \mathrm{C}$ and $T_{R 102}=200{ }^{\circ} \mathrm{C}$ on the same interval of sorbent to $\mathrm{CO}_{2}$ ratios are presented in Figure 8. Both the carbonator cooling and calciner heating duty represent the largest contributions to the system's overall energy intensity. The energy penalty associated is therefore minimised for $\dot{Q}_{H}=\dot{Q}_{C}$. This is satisfied for $\dot{n}_{\mathrm{Na}_{2} \mathrm{CO}_{3}} \dot{n}_{\mathrm{CO}_{2}}^{-1}=2.5$.

\subsection{Gibbs Free Energy Minimisation}

The RGIBBS reactor blocks presented throught this chapter are based on the principle of Gibbs free energy minimisation. In this section, calciner reactor outlet compositions as predicted by Aspen Plus V9 are validated against a simple thermodynamic model describing the dependence of Gibbs free energy with respect to changes in various operating parameters is outlined. Specific heat capacity data utilised throughout 
Accounting for the possibility of sodium sulfate formation due to the presence of $\mathrm{SO}_{2}$ in the flue gas stream, previously developed expressions for individual and total molar for Calculating Thermodynamic Properties of Individual Species [33] for all remaining components. A detailed analysis and derivation of all formulae obtained is presented in Appendix A and Appendix B.

As carbonator and calciner units employed in this thesis operate at atmospheric pressures, it is assumed that ideal gas model approximates the Gibbs free energy of the respective system sufficiently well. Each of the latter reactor block employed is a heterogenious two-phase system. Within the range of carbonator operating temperatures of $T<100{ }^{\circ} \mathrm{C}$, the sorbent is suspended as water present is in the liquid phase. Equilibrium data for various sodium carbonates and hydrate salts at $0 \leq T \leq 200{ }^{\circ} \mathrm{C}$ in solution has been outlined in Section 2.2. In contrast, calciner operating temperatures exceed $200{ }^{\circ} \mathrm{C}$, making the reactor a solid-gas system. For the two phases $j=\{\alpha, \beta\}$ and all components $i=\{1,2, \ldots, k\}$ present, the system's total Gibbs free energy at reference pressure is given by

$$
G_{T}^{s y s}=\sum_{j=\alpha, \beta} \sum_{i=1}^{k} \mu_{i}^{j} n_{i}^{j}=\sum_{j=\alpha, \beta} \sum_{i=1}^{k}\left[\mu^{(i g)}(T)+R T \ln \left(\frac{n_{i}^{j}}{n^{j}}\right)\right] n_{i}^{j} .
$$

Bisecting each individual flow rate $n_{i}^{j}$ and total flow rate $n^{j}$ into the amounts initially present, here denoted with the subscript 0 , and reacted off according to

$$
n_{i}^{j}=n_{i, 0}^{j}+\nu_{i}^{j} \xi \quad \text { and } \quad n^{j}=\sum_{i=1}^{k} n_{i}^{j}=\sum_{i=1}^{k}\left(n_{i, 0}^{j}+\nu_{i} \xi\right)=n_{0}^{j}+\nu^{j} \xi,
$$

$G_{T}^{s y s}$ can be minimised with respect to the reaction coordinate $\xi$. The corresponding derivative $\frac{\left(d G_{T}^{(s y s)}\right)_{T, P}}{d \xi}$ is found to be

$$
\frac{\left(d G_{T}^{(s y s)}\right)_{T, P}}{d \xi}=\frac{d n_{i}^{j}}{d \xi} \frac{\left(G_{T}^{(s y s)}\right)_{T, P}}{n_{i}^{j}},
$$

Exemplary results of plotting Equation 16 and 18 as a function of reaction extent for $\mathrm{Na}_{2} \mathrm{CO}_{3}$ carbonation at $\mathrm{T}=60{ }^{\circ} \mathrm{C}$ is shown in Figure 9 . It can be observed that the Gibbs free energy minimum is coinciding with the root of its derivative.

Hence an extent of reaction of $\xi=65 \mathrm{~mol} \mathrm{~s}^{-1}$ satisfies the general condition for the existence of a local extremum, $\frac{\left(d G_{T}^{\text {sys }}\right)_{T, P}}{d \xi}=0$. Neglecting the occurence of other reactions and assuming the validity of the thermodynamic model created, this indicates that $\mathrm{Na}_{2} \mathrm{CO}_{3}$ carbonation does proceed at the chosen operating conditions.

this section is taken from [28] for $\mathrm{NaHCO}_{3(s)}$ and from the NASA Glenn Coefficients in the flue gas stream, previously developed expressions for individual and total molar 


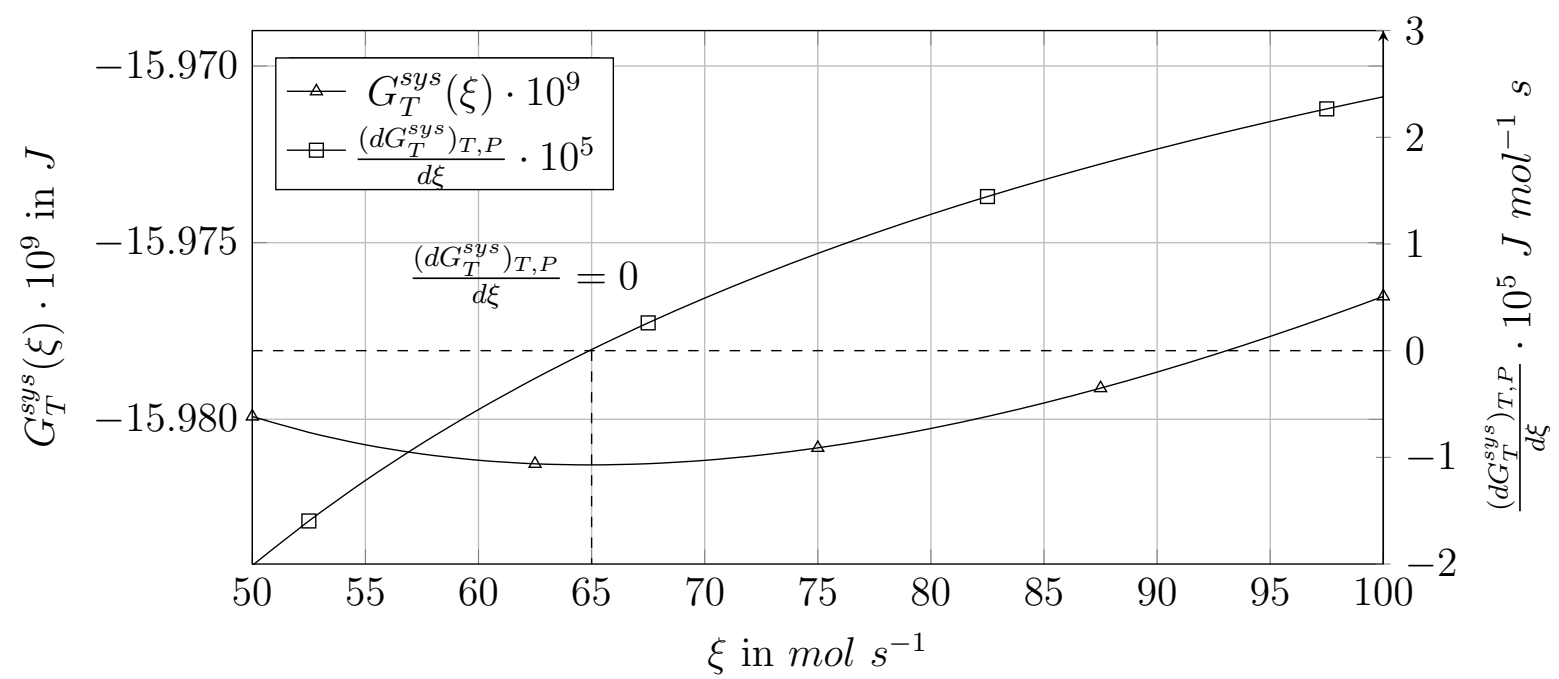

Figure 9: Carbonator Gibbs free energy $G_{T}^{s y s}(\xi)$ in $J$ and its derivative $\frac{\left(d G_{T}^{s y s}\right)_{T, P}}{d \xi}$ in $J m^{-1} s$ as a function of reaction coordinate $\xi$ in $\mathrm{mol} \mathrm{s}{ }^{-1}$ at $\mathrm{T}=60{ }^{\circ} \mathrm{C}$ for a $\mathrm{CO}_{2}$ to sorbent ratio of $n_{\mathrm{CO}_{2}} n_{\mathrm{Na}_{2} \mathrm{CO}_{3}}^{-1}=$ 0.25 .

flow rates $n_{i}^{j}$ and $n^{j}$ must be revised. For a system of 2 reactions,

$$
\begin{aligned}
& \mathrm{Na}_{2} \mathrm{CO}_{3}+\mathrm{CO}_{2}+\mathrm{H}_{2} \mathrm{O} \rightleftharpoons 2 \mathrm{NaHCO}_{3} \\
& \mathrm{Na}_{2} \mathrm{CO}_{3}+\mathrm{SO}_{2}+\frac{1}{2} \mathrm{O}_{2} \rightleftharpoons \mathrm{Na}_{2} \mathrm{SO}_{4}+\mathrm{CO}_{2}
\end{aligned}
$$

Equation 16 can be constrained by an atomic mass balance such that the number of atoms initially added $b_{e q}$ satisfies

$$
\min _{\vec{x}} G_{T}^{s y s}=f(\vec{x})=f\left(n_{1}^{j}, n_{2}^{j}, \ldots, n_{i}^{j}\right), \quad \text { such that } \quad A_{e q} \cdot \vec{x}=b_{e q},
$$

where $\vec{x}=\left[n_{1}^{j}, n_{2}^{j}, \ldots, n_{i}^{j}\right]$ is the vector of all individual flow rates of species $i$ in phase $j$ and $A_{e q}$ represents the matrix of number of atoms present in every compound. The atomic balance corresponding to all species considered is:

$$
\mathrm{A}_{e q}=\left(\begin{array}{ccccccccc}
\mathrm{Na}_{2} \mathrm{CO}_{3} & \mathrm{CO}_{2} & \mathrm{H}_{2} \mathrm{O} & \mathrm{NaHCO}_{3} \mathrm{Na}_{2} \mathrm{SO}_{4} & \mathrm{SO}_{2} & \mathrm{~N}_{2} & \mathrm{O}_{2} & \mathrm{CO} \\
0 & 2 & 1 & 3 & 4 & 2 & 0 & 2 & 1 \\
0 & 0 & 2 & 1 & 0 & 0 & 0 & 0 & 0 \\
1 & 1 & 0 & 1 & 0 & 0 & 0 & 0 & 1 \\
2 & 0 & 0 & 1 & 2 & 0 & 0 & 0 & 0 \\
0 & 0 & 0 & 0 & 1 & 1 & 0 & 0 & 0 \\
0 & 0 & 0 & 0 & 0 & 0 & 2 & 0 & 0
\end{array}\right)_{N}
$$

so Subsequent to the definition of atomic balance constraint, the minimisation procedure is realised utilising the MATLAB function fmincon. Based on interior point optimisation algorithms, the linear programming solver fmincon minimises $G_{T}^{\text {sys }}$ as a function 
of various molar flow rates such that Equation 21 is satisfied [34]. In addition to initial amounts of species present, the optimisation was further constrained by the lower bound of atomic flow rates $\vec{x}_{l b}=\overrightarrow{0}$.

Applying this modified minimisation procedure to reactor R102 inlet composition displayed in Table 2, Stream 5 at the previously defined temperature optimum $T_{R 102}=$ $200{ }^{\circ} \mathrm{C}$ replicates the extent of calcination and sorbent degradation predicted by the Aspen model created. Effluent calciner flow rates of both programmes in $\mathrm{kmol} \mathrm{hr}^{-1}$ are summarised in Table 5. It is evident that at the chosen R102 operating temperature, $\mathrm{NaHCO}_{3}$ calcination virtually runs to completion.

Table 5: Comparison of R102 outlet flow rates in $\mathrm{kmol} \mathrm{hr}^{-1}$ at $T_{R 102}$ predicted by the Gibbs free energy minimisation model implemented in MATLAB and by the Aspen simulation created relative to an inlet flow rate composition $\dot{n}_{i, i n}$.

\begin{tabular}{lccccccccc} 
& $\mathrm{Na}_{2} \mathrm{CO}_{3}$ & $\mathrm{CO}_{2}$ & $\mathrm{H}_{2} \mathrm{O}$ & $\mathrm{NaHCO}_{3}$ & $\mathrm{Na}_{2} \mathrm{SO}_{4}$ & $\mathrm{SO}_{2}$ & $\mathrm{~N}_{2}$ & $\mathrm{O}_{2}$ & $\mathrm{CO}$ \\
\hline$\dot{n}_{i, \text { in }}$ & 12037.1 & 0 & 0 & 19946.1 & 6559.0 & 0 & 0 & 0 & 0 \\
\hline MATLAB & 22010.1 & 9973.0 & 9973.0 & $1.0309 \cdot 10^{-14}$ & 6558.9 & $2.1146 \cdot 10^{-18}$ & $1.0573 \cdot 10^{-13}$ & $2.1147 \cdot 10^{-17}$ & 0.0276 \\
Aspen & 22010.1 & 9973.0 & 9973.0 & 0 & 6559.0 & 0 & 0 & 0 & 0 \\
\hline
\end{tabular}

Minor deviations in the flow rates computed are likely due to differences in the equation-oriented approach of the model created in MATLAB and the default sequential modular approach and the associated tolerances utilised by Aspen. This leads to the conclusion that the ideal gas, two-phase thermodynamic model created describes the extent of calcination and sorbent depletion sufficiently well.

\subsection{Environmental Performance}

To assess and compare the environmental performance of the process developed in Section 2 to existing carbon capture processes, two metrics, the energy penalty and the SPECCA value are employed in this manuscript.

Energy penalty is the fraction of energy relative to the gross power output of a plant that must be sacrificed to capture $\mathrm{CO}_{2}$ contained in its flue gas stream [35]. For a total power output of $\dot{Q}_{\text {total }}$, the net amount of energy produced deducting the energy dedicated to capture $C \mathrm{O}_{2}$ is given by $\dot{Q}_{n e t}=\dot{Q}_{\text {total }}-\left|\dot{Q}_{\text {capt }}\right|$. It follows that percentage energy penalty $\eta_{\text {pen }}$ equates to

$$
\eta_{p e n}=\frac{\left|\dot{Q}_{c a p t}\right|}{\dot{Q}_{n e t}}=\frac{\left|\dot{Q}_{c a p t}\right|}{\dot{Q}_{\text {total }}-\left|\dot{Q}_{\text {capt }}\right|} .
$$

Changes in energy penalty of the base-case and final process model presented as a function of capture efficiency are presented in Figure 10. It is evident that the correlation of both models is fundamentally different. As oppose to base-case energy penalties monotonously increasing on the interval of capture efficiencies investigated, values for the final process decrease linearly for $73.89 \leq \eta_{\text {capt }} \leq 85.51 \%$. For $\eta_{\text {capt }} \rightarrow 100 \%$ 

energy penalty maximum is $11.89 \%$, corresponding to a capture efficiency of $98.93 \%$.

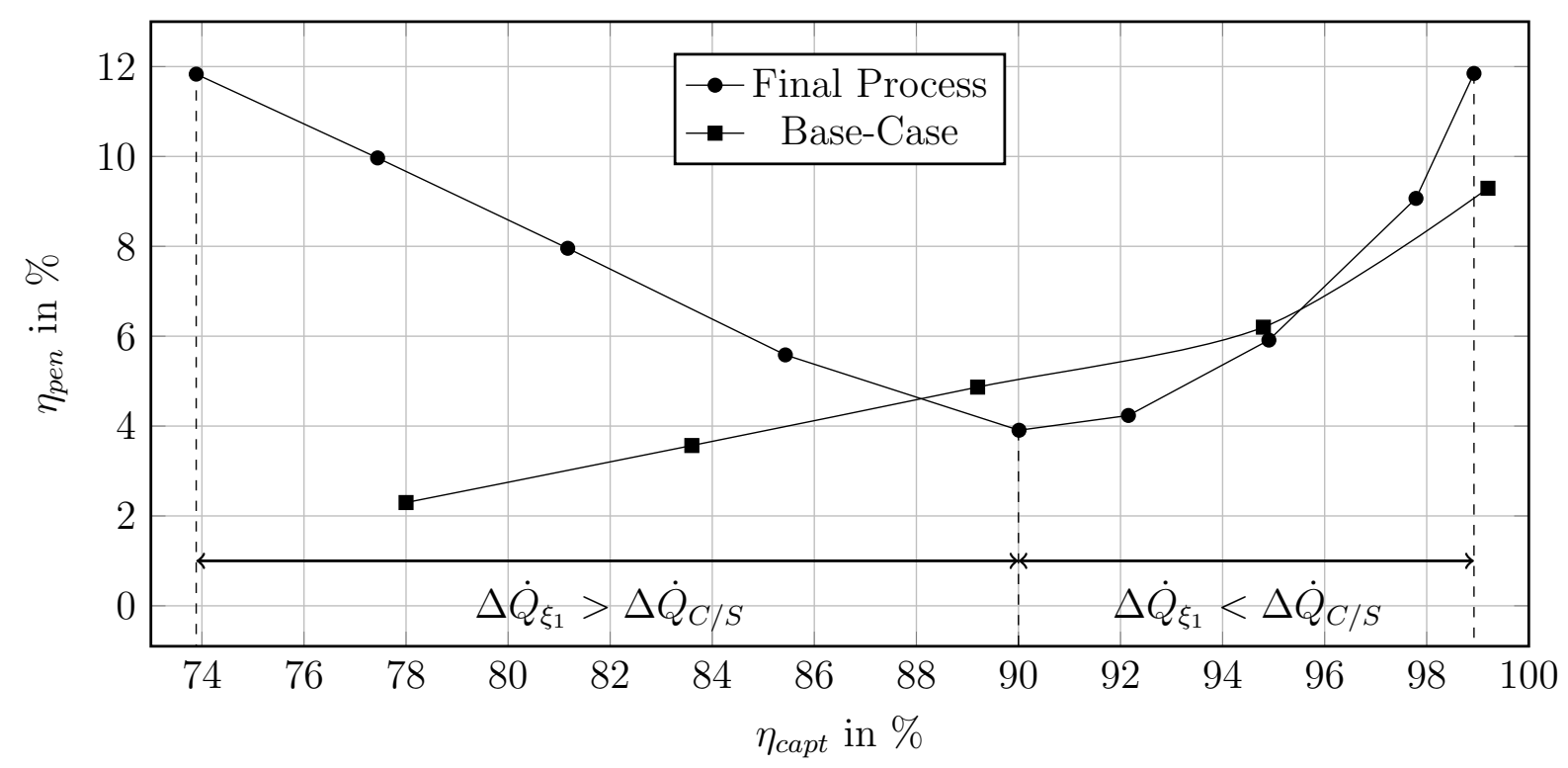
incoming $\mathrm{CO}_{2}$ increases in a non-linear fashion. The respective final process marginal

Figure 10: Comparison of changes in energy penalty $\eta_{p e n}$ as a function of $\mathrm{CO}_{2}$ capture efficiency between the final and the base-case process.

however, both graphs surge as the energy sacrificed to capture a higher portion of the

Initially observed reductions in energy penalty for $73.89 \leq \eta_{\text {capt }} \leq 90.00 \%$ arise as a consequence of changes introduced to the sorbent to $\mathrm{CO}_{2}$ ratio. At constant operating temperatures of $T_{R 101}=20{ }^{\circ} \mathrm{C}$ and $T_{R 102}=200{ }^{\circ} \mathrm{C}$, the progression of $\eta_{\text {pen }}=f\left(\eta_{\text {capt }}\right)$ is governed by the the amount of excess sorbent present in the system relative the inlet $\mathrm{CO}_{2}$ flow rate. As the ratio of $\dot{n}_{\mathrm{Na}_{2} \mathrm{CO}_{3}}: \dot{n}_{\mathrm{CO}_{2}}$ increases, increments in R101 cooling duty $\Delta \dot{Q}_{\xi_{1}}$ due to a higher extent of carbonation $\xi_{1}$ are accelerated over the rate of R102 heating duty increments resultant of a higher total mass flow-rate recirculated $\Delta \dot{Q}_{C / S}$. By analogous reasoning, rising calciner heating duties outweigh the effect of progressively increasing $\xi_{1}$ on carbonator cooling duties for $\eta_{\text {capt }} \rightarrow 100 \%$. Corresponding to the previously determined optimal $\dot{n}_{\mathrm{Na}_{2} \mathrm{CO}_{3}}: \dot{n}_{\mathrm{CO}_{2}}=2.5$, carbonator and calciner duties $\dot{Q}_{C}$ and $\dot{Q}_{H}$ are matching, resulting in a local energy penalty minimum of $3.99 \%$ at $\eta_{\text {capt }}=90.00 \%$. At this capture efficiency, the energy penalty minimum achieved outperforms comparable calcium oxide looping processes as presented in [36] by an estimated $2 \%$. It is important to mention that energy expenses associated with the make-up of depleted sorbent is included in the analysis of this chapter. In contrast, benchmark calcium looping energy penalties the process developed is compared against neglect these expenses. Consequently, the true net energy penalty difference of both looping schemes is likely to be larger.

The Specific Primary Energy Consumption for $\mathrm{CO}_{2}$ Avoided (SPECCA) value is indicative of the integrated capture plant's overall energy requirement per unit of $\mathrm{CO}_{2}$ emission mitigated with respect to its reference plant. [37]. Taking $\eta$ and $\eta_{\text {ref }}$ to be 
the total process and reference power plant efficiencies, the specific primary energy consumption in $\mathrm{MJ}$ per $\mathrm{kgCO}$ avoided is computed as

$$
\mathrm{SPECCA}=3600 \frac{\frac{1}{\eta}-\frac{1}{\eta_{r e f}}}{E_{r e f}-E} .
$$

Here, $E$ and $E_{\text {ref }}$ correspond to the respective integrated and reference plant emission ratios in $\mathrm{kg} \mathrm{CO}_{2} \mathrm{kWh}^{-1}$ [38]. Arising from the reference power plant gross power output of $600 \mathrm{MW}$ and the integrated process $\mathrm{CO}_{2}$ flow rates corresponding to the local energy penalty minimum at $\eta_{\text {capt }}=90 \%$ as presented Table 3 , the respective emission ratios are found to be $E_{r e f}=0.6579 \mathrm{kgCO}_{2} \mathrm{kWh}^{-1}$ and $E=9.98810^{-3} \mathrm{~kg} \mathrm{CO}_{2} \mathrm{kWh}^{-1}$. Additionally taking the reference power plant efficiency to be $\eta=0.4493[18,39]$, Equation 23 is evaluated to be SPECCA $=0.514 \mathrm{MJ} \mathrm{kg} \mathrm{CO}_{2}^{-1}$. Table 6 summarises metrics indicative of the environmental performance of calcium looping and amine scrubbing capture schemes discussed in Section 1 and those of the sodium carbonate-based capture scheme employed in this paper.

Table 6: Comparison of the Specific Primary Energy Consumption for $\mathrm{CO}_{2}$ Avoided (SPECCA) indices in $M J \mathrm{~kg} \mathrm{CO}_{2}^{-1}$ of various carbon capture schemes.

\begin{tabular}{|c|c|c|c|}
\hline & $\begin{array}{l}\text { Calcium-based } \\
\text { looping }\end{array}$ & Amine scrubbing & $\begin{array}{l}\text { Sodium-based } \\
\text { looping }\end{array}$ \\
\hline Source & {$[40]$} & {$[41]$} & This Paper \\
\hline $\begin{array}{l}\text { Overall gross power out- } \\
\text { put, } M W\end{array}$ & 546.7 & 299.4 & 600.0 \\
\hline Energy Penalty, \% & 4.96 & 7.80 & 3.99 \\
\hline SPECCA, MJ $k g \mathrm{CO}_{2}^{-1}$ & 5.897 & 10.238 & 0.514 \\
\hline
\end{tabular}

Both in terms of the energy penalty and SPECCA index, sodium-carbonate based capture schemes are identified to outperform currently existing retrofit processes. Despite the significant differences in SPECCA indices across all capture schemes, it must be noted that a direct comparison is only possible to a limited extend. Vorrias et al. [40], Doukelis and Koumanakos [41] accommodate for the energy expense needed to compress the purified outlet $\mathrm{CO}_{2}$ stream, whilst the duties of process units involved in the solids make-up are neglected. In contrast, components associated with the breakdown of trona and the make-up stream preparation are accounted for in this paper. The energy expense associated with pressurising the outlet $\mathrm{CO}_{2}$ up to storage quality is not incorporated. It must be furthermore noted that the overall gross power output, flue gas stream composition and $\mathrm{CO}_{2}$ partial pressure varies across all 3 cases. Moreover, the energy penalty and SPECCA index are a function of the net duties of unit operations involved. They hence depend on the effectiveness of heat integration amongst these components. A valid comparison across all 3 capture schemes presented is therefore only possible if firstly, all parameters characterising the inlet flue gas stream are normalised to the same 
reference plant. Secondly, auxiliary process streams incorporating make-up preparation prior, and/or $\mathrm{CO}_{2}$ compression subsequent to the capture scheme must be uniform with in the investigation margin considered.

Despite these promising initial results, the data generated has to be interpreted with care. In order to draw a relevant conclusion regarding the feasibility of sodium carbonate-based looping cycles, the remaining assumptions made in the final process model presented in Section 2 must be validated. The investigation of sorbent depletion is assessed by solely considering a representative reaction between sodium carbonate and and sulphur dioxide. This idealisation underestimates the true extent of degradation, as various other mechanisms [30] effectively reducing the amount of sodium carbonate available for carbonation are neglected.

It was pointed out that the effectiveness of post-combustion $\mathrm{CO}_{2}$ capture is dependant on the flue gas composition and therefore on the choice of stationary point source. Even though changes in $\mathrm{SO}_{2}$ volume fraction are investigated, the amount of $\mathrm{CO}_{2}$ contained in the inlet flue gas stream is kept constant at all times. The parametric process optimisation presented aims on maximising the amount of $\mathrm{CO}_{2}$ captured, whilst retaining the lowest energy penalty possible for that respective capture efficiency. These performance indicators tabulated for both the base-case and the final process neglect the effect of solids particle size, crystalline structure and porosity on the rate of reaction. The economic and ecologic liabilities associated with the capture scheme proposed can only be determined by incorporating the effect of above parameters into the optimisation procedure.

\section{Conclusion}

In the pursuit of exploring the substantial potential of carbonate looping schemes towards zero-emission carbon capture, it can be said that sodium carbonate is an efficient alternative to commercially available processes. In this paper, it has shown that:

- Sodium carbonate-based capture schemes retrofitted to a $600 \mathrm{MW}$ reference coalfired power plant allow for a total of $90.00 \%$ of the incoming $\mathrm{CO}_{2}$ to be captured.

- The resulting concentrated outlet $\mathrm{CO}_{2}$ stream has a purity of $99.90 \%$.

- The process features a distinct energy penalty minimum of $\eta_{p e n}=3.99 \%$, corresponding to a capture efficiency of $90.00 \%$.

- Predicted capture efficiencies are stable across a range of $\mathrm{SO}_{2}$ flue gas volume fractions, obviating the need for desulphurisation pre-treatment.

- $\mathrm{NaHCO}_{3}$ calcination extents are accurately predicted by a two-phase, multiple reaction thermodynamic equilibrium model based on the principle of Gibbs free energy minimisation. 
The assessment carried out accommodates for auxiliary process streams involved in the breakdown of trona and the replenishment of degraded $\mathrm{Na}_{2} \mathrm{CO}_{3}$, however, does not account for the duties involved in compressing the captured $\mathrm{CO}_{2}$ up to storage quality. The SPECCA index corresponding to this scope of investigation amounts to $0.514 \mathrm{MJ} \mathrm{kg} \mathrm{CO}{ }_{2}^{-1}$. Evaluating the competitive performance of novel carbon capture technology from an ecological and thermodynamic viewpoint requires a uniform scope of investigation across all capture schemes compared. A holistic examination of the processes net environmental benefit is therefore only representative if auxiliary processes including a $\mathrm{CO}_{2}$ compression train and the ecological footprint associated with crushing and mining trona are incorporated into the models scope. Likewise, mass transfer limitations, the true extend of sorbent depletion and the overall process performance sensitivity to changes in inlet $\mathrm{CO}_{2}$ volume fractions must be considered. 


\section{Appendix A. Total Gibbs Free Energy}

The total value of any extensive property considered in this chapter $M_{T}\{M \equiv$ $G, H, S\}$ depends on temperature, pressure and the number of moles of each respective species $i \in\{1,2, \ldots, k\}$ in the system such that $M_{T}=n M=f\left\{T, P, n_{1}, n_{2}, \ldots, n_{k}\right\}$. Correspondingly, the total derivative of any of these extensive property is

$$
\begin{aligned}
d\left(M_{T}\right)=d(n M) & =\left(\frac{\partial(n M)}{\partial P}\right)_{T, n} d P+\left(\frac{\partial(n M)}{\partial T}\right)_{P, n} d T+\left(\frac{\partial(n M)}{\partial n_{i}}\right)_{T, P, n_{i \neq j}} d n_{i} \\
& =n\left(\frac{\partial M}{\partial P}\right)_{T, x} d P+n\left(\frac{\partial M}{\partial T}\right)_{P, x} d T+n \sum_{i=1}^{k} \bar{M}_{i} d x_{i},
\end{aligned}
$$

where, by definition,

$$
\bar{M}_{i}=\left(\frac{\partial(n M)}{\partial n_{i}}\right)_{T, P, n_{i \neq j}},
$$

denotes the partial molar property, i.e. the change of total property $M_{T}$ of a mixture with $k$ species due to the addition of infinitesimal amounts of species $i$ to that mixture at constant temperature and pressure [42]. Here, the subscript $i \neq j$ denotes that the number of moles of component $i$ vary, whilst $n_{i \neq j}$ are kept constant. The importance of the total derivative lies in the fact that extensive, non-measurable thermodynamic potentials can be directly linked to measurable properties they are a function of.

Applying Equation A.2 to the system's total Gibbs free energy $G_{T}=\left\{T, P, n_{1}, n_{2}, \ldots, n_{k}\right\}$ yields

$$
d\left(G_{T}\right)=d(n G)=n\left(\frac{\partial G}{\partial P}\right)_{T, x} d P+n\left(\frac{\partial G}{\partial T}\right)_{P, n} d T+\sum_{i=1}^{k} \bar{G}_{i} d n_{i}
$$

The partial molar Gibbs free energy is referred to as chemical potential

$$
\bar{G}_{i}=\mu_{i}=\left(\frac{\partial(n G)}{\partial n_{i}}\right)_{T, P, n_{i \neq j}}
$$

Keeping the two natural variables $T$ and $P$ constant and applying the product rule to both $d\left(G_{T}\right)=d(n G)$ and $d\left(n_{i}\right)=d\left(n x_{i}\right)$, Equation A.3 can be further simplified to

$$
G=\sum_{i=1}^{k} \bar{G}_{i} x_{i} \quad \text { and } \quad G_{T}=\sum_{i=1}^{k} \bar{G}_{i} n_{i} \quad \text { at } T, P=\text { constant } .
$$

It can furthermore be shown that the ideal gas chemical potential $\mu^{(i g)}$ can be expressed by

$$
\mu^{(i g)}(T, P)=\mu^{(i g)}(T)+R T \ln \left(\frac{P}{P_{0}}\right)+R T \ln \left(\frac{n_{i}}{n_{\alpha}}\right)
$$

where $P_{0}$ and $n_{\alpha}$ refer to the reference state pressure and the total number of moles in phase $\alpha$, respectively [43]. Moreover, the isobaric temperature dependant contribution 
of component $i$,

$$
\mu_{i}^{(i g)}(T)=H_{i}^{(i g)}(T)-T S_{i}^{(i g)}(T),
$$

can be expressed as a function of the specific heat capacity of that respective component at reference pressure. As the fundamental thermodynamic relationship relating enthalpy $H$ and entropy $S$ to PVT properties,

$$
d H=T d S+V d P
$$

reduces to

$$
d H=T d S \quad \leftrightarrow \quad \frac{1}{T}\left(\frac{\partial H}{\partial T}\right)_{P}=\frac{C_{P}}{T}=\left(\frac{\partial S}{\partial T}\right)_{P}
$$

$$
H^{(i g)}(T)-H_{T_{0}}^{(i g)}=\int_{T_{0}}^{T} a_{n} T^{n} d T \quad \text { and } \quad S^{(i g)}(T)-S_{T_{0}}^{(i g)}=\int_{T_{0}}^{T} a_{n} T^{n-1} d T .
$$

It follows that

$$
H^{(i g)}(T)=a_{-1} \ln (T)+\sum_{n \neq-1} \frac{a_{n}}{n+1} T^{n+1}+H_{T_{0}}^{(i g)}
$$

and

$$
S^{(i g)}(T)=a_{0} \ln (T)+\sum_{n \neq 0} \frac{a_{n}}{n} T^{n}+S_{T_{0}}^{(i g)} .
$$

where $a_{-1}$ and $a_{0}$ refer to the coefficients of the terms $T^{-1}$ and $T^{0}$. Substituting Equations A.11 and A.12 back into A.7 [43], the chemical potential is hence expressed as

$$
\mu_{i}^{(i g)}(T)=a_{-1} \ln (T)+\sum_{n \neq-1} \frac{a_{n}}{n+1} T^{n+1}+H_{T_{0}}^{(i g)}-T\left(a_{0} \ln (T)+\sum_{n \neq 0} \frac{a_{n}}{n} T^{n}+S_{T_{0}}^{(i g)}\right) .
$$

Gathering terms together yields

$$
\mu_{i}^{(i g)}(T)=\left(a_{-1}-T a_{0}\right) \ln (T)+a_{-1}+T a_{0}-\sum_{n \neq-1,0} \frac{a_{n}}{n(n+1)} T^{n+1}+H_{T_{0}}^{(i g)}-T S_{T_{0}}^{(i g)} .
$$

\section{Appendix B. Derivation of Equation 18}

Considering one single heterogeneous reaction, molar flow rates of component $i$ in phase $j n_{i}^{j}$ can be expressed as a function of reaction extent $\xi$. For a generic reaction, the change in number of moles relative to the stoichiometry of any component is preserved and equals the change of reaction coordinate $d \xi$. In essence, the stoichiometric molar turnover of reactants into products or vice versa the generation of products from 
reactants can be written as

$$
d \xi \equiv \frac{d n_{1}^{\alpha}}{\nu_{1}}=\frac{d n_{2}^{\beta}}{\nu_{2}}=\frac{d n_{3}^{\gamma}}{\nu_{3}}=\ldots=\frac{d n_{i}^{j}}{\nu_{i}}
$$

Assuming that at time $t=0$, the reaction is initiated and $n_{i, 0}^{j}$ moles of species $i$ in phase $j$ are initially present, the above expression can be integrated [44]

$$
\int_{n_{i, 0}^{j}}^{n_{i}^{j}} d n_{i}^{j}=\nu_{i}^{j} \int_{0}^{\xi} d \xi
$$

It follows that

$$
n_{i}^{j}-n_{i, 0}^{j}=\nu_{i}^{j} \xi \quad \text { and } \quad n_{i}^{j}=n_{i, 0}^{j}+\nu_{i}^{j} \xi .
$$

93 The total molar flow rate in each respective phase $n^{j}$ is hence

$$
n^{j}=\sum_{i=1}^{k} n_{i}^{j}=\sum_{i=1}^{k}\left(n_{i, 0}^{j}+\nu_{i} \xi\right)=n_{0}^{j}+\nu^{j} \xi,
$$

where $n_{0}^{j}=\sum_{i=1}^{k} n_{i, 0}^{j}$ is the sum of the initial number of moles present in phase $j$ and correspondingly, $\nu^{j}=\sum_{i=1}^{k} \nu_{i}^{j}$ denotes the sum of all component's stoichiometric coefficients in that phase. Assuming the calciner block reactions proceed to reach equilibrium,

$$
d\left(G_{T}^{s y s}\right)_{T, P}=d\left(\sum_{j=\alpha, \beta} \sum_{i=1}^{k} \mu_{i}^{j} n_{i}^{j}\right)_{T, P}=0 .
$$

Carrying out the differentiation with respect to $\xi$ yields

$$
\begin{aligned}
\frac{\left(d G_{T}^{(s y s)}\right)_{T, P}}{d \xi} & =\sum_{j=\alpha, \beta} \sum_{i=1}^{k}\left[\nu_{i}^{j}\left(\mu_{i}^{(i g)}(T)+R T \ln \left(\frac{n_{i}^{j}}{n^{j}}\right)\right)+\frac{R T}{\left(n_{0}^{j}+\nu^{j} \xi\right)}\left(\nu_{i}^{j} n_{0}^{j}-\nu^{j} n_{i, 0}^{j}\right)\right] \\
& =\sum_{j=\alpha, \beta} \sum_{i=1}^{k} \nu_{i}^{j}\left[\mu_{i}^{(i g)}(T)+R T \ln \left(\frac{n_{i}^{j}}{n^{j}}\right)\right]+\frac{R T}{\left(n_{0}^{j}+\nu^{j} \xi\right)} \sum_{j=\alpha, \beta} \sum_{i=1}^{k}\left[\nu_{i}^{j} n_{0}^{j}-\nu^{j} n_{i, 0}^{j}\right] \\
& =\sum_{j=\alpha, \beta} \sum_{i=1}^{k} \nu_{i}^{j}\left[\mu_{i}^{(i g)}(T)+R T \ln \left(\frac{n_{i}^{j}}{n^{j}}\right)\right] \\
& =\frac{d n_{i}^{j}}{d \xi} \frac{\left(G_{T}^{(s y s)}\right)_{T, P}}{n_{i}^{j}},
\end{aligned}
$$

as as by definition $\sum_{j=\alpha, \beta} \sum_{i=1}^{k} \nu_{i}^{j} n_{0}^{j}=\sum_{j=\alpha, \beta} \sum_{i=1}^{k} \nu^{j} n_{i, 0}^{j}$. 


\begin{tabular}{|c|c|c|c|}
\hline \multicolumn{4}{|c|}{ Nomenclature } \\
\hline C101 & Inlet flue gas compressor & $C_{P}$ & Specific heat capacity \\
\hline E101 & Mixed recycling stream cooler & $\xi$ & Extent of reaction \\
\hline E102 & S102 inlet cooler & $G_{T}^{\text {sys }}$ & Total Gibbs free energy \\
\hline E103 & S101 tops products cooler & $H$ & Enthalpy \\
\hline E104 & Outlet $\mathrm{CO}_{2}$ water condenser & $\mu_{i}$ & Chemical potential \\
\hline E105 & R103 inlet heater & $\mathcal{N}$ & Number of cycles \\
\hline P101 & Mixed recycling stream pump & $\dot{n}_{i}$ & Molar flow rate of component $i$ \\
\hline P102 & Trona brine feed pump & $\eta$ & Isentropic efficiency \\
\hline R101 & Carbonator reactor unit & $\eta_{\text {capt }}$ & Capture efficiency \\
\hline R102 & Calciner reactor unit & $\eta_{p e n}$ & Energy penalty \\
\hline R103 & Calciner reactor unit & $S$ & Entropy \\
\hline $\mathrm{S} 101$ & R101 products solid-gas separator & $T$ & Temperature \\
\hline $\mathrm{S} 102$ & R102 products solid-gas separator & $\nu$ & Stoichiometric coefficient \\
\hline
\end{tabular}

\section{References}

[1] R. K. Pachauri, M. R. Allen, V. R. Barros, J. Broome, W. Cramer, R. Christ, J. A. Church, L. Clarke, Q. Dahe, P. Dasgupta, et al., Climate change 2014: Synthesis report. Contribution of Working Groups I, II and III to the fifth assessment report of the Intergovernmental Panel on Climate Change, IPCC, Geneva, Switzerland, 2014.

[2] T. A. Boden, R. J. Andres, G. Marland, Global, Regional, and National FossilFuel $\mathrm{CO}_{2}$ Emissions (1751-2010)(V. 2013), Technical Report, Carbon Dioxide Information Analysis Center (CDIAC), Oak Ridge National Laboratory (ORNL), Oak Ridge, TN (United States), 2013.

[3] N. V. von der Aßen, From life-cycle assessment towards life-cycle design of carbon dioxide capture and utilization, $\mathrm{PhD}$ Dissertation, Rheinisch-Westfälische Technische Hochschule Aachen, 2015.

[4] P. Styring, D. Jansen, H. De Coninck, H. Reith, K. Armstrong, Carbon capture and utilisation in the green economy, 1 ed., Centre for Low Carbon Futures, New York, USA, 2011.

[5] D. P. Hanak, C. Biliyok, E. J. Anthony, V. Manovic, Modelling and comparison of calcium looping and chemical solvent scrubbing retrofits for $\mathrm{CO}_{2}$ capture from coal-fired power plant, International Journal of Greenhouse Gas Control 42 (2015) $226-236$. 
[6] G. P. Hammond, J. Spargo, The prospects for coal-fired power plants with carbon capture and storage: A UK perspective, Energy Conversion and Management 86 (2014) 476-489.

[7] J. Hedström, Simulation and assessment of carbon capture processes applied to a pulp mill, MSc Dissertation, Chalmers University of Technology, 2014.

[8] B. P. Spigarelli, S. K. Kawatra, Opportunities and challenges in carbon dioxide capture, Journal of $\mathrm{CO}_{2}$ Utilization 1 (2013) 69-87.

[9] R. Bottoms, Separating acid gases, U.S. Patent 1783901, 1930.

[10] H. Herzog, J. Meldon, A. Hatton, Advanced post-combustion $\mathrm{CO}_{2}$ capture, Massachusetts Institute of Technology (2009).

[11] A. Kothandaraman, Carbon dioxide capture by chemical absorption: A solvent comparison study, PhD Dissertation, Massachusetts Institute of Technology, 2010.

[12] G. Xu, H. Jin, Y. Yang, Y. Xu, H. Lin, L. Duan, A comprehensive techno-economic analysis method for power generation systems with $\mathrm{CO}_{2}$ capture, International Journal of Energy Research 34 (2010) 321-332.

[13] G. Cau, D. Cocco, V. Tola, Performance assessment of USC power plants integrated with CCS and concentrating solar collectors, Energy Conversion and Management 88 (2014) 973-984.

[14] R. Zhao, S. Deng, L. Zhao, Y. Liu, Y. Tan, Energy-saving pathway exploration of CCS integrated with solar energy: Literature research and comparative analysis, Energy Conversion and Management 102 (2015) 66-80.

[15] J. Ströhle, A. Galloy, B. Epple, Feasibility study on the carbonate looping process for post-combustion $\mathrm{CO}_{2}$ capture from coal-fired power plants, Energy Procedia 1 (2009) 1313-1320.

[16] P. Fennell, J. Davidson, J. Dennis, A. Hayhurst, Regeneration of sintered limestone sorbents for the sequestration of $\mathrm{CO}_{2}$ from combustion and other systems, Journal of the Energy Institute 80 (2007) 116-119.

[17] M. Ramezani, K. Shah, E. Doroodchi, B. Moghtaderi, Application of a novel calcium looping process for production of heat and carbon dioxide enrichment of greenhouses, Energy Conversion and Management 103 (2015) 129-138.

[18] Y. Yang, R. Zhai, L. Duan, M. Kavosh, K. Patchigolla, J. Oakey, Integration and evaluation of a power plant with a $\mathrm{CaO}$-based $\mathrm{CO}_{2}$ capture system, International Journal of Greenhouse Gas Control 4 (2010) 603-612.

[19] D. P. Hanak, S. Michalski, V. Manovic, From post-combustion carbon capture to sorption-enhanced hydrogen production: A state-of-the-art review of carbonate looping process feasibility, Energy Conversion and Management 177 (2018) 428-452. 
[20] L. M. Romeo, Y. Lara, P. Lisbona, J. M. Escosa, Optimizing make-up flow in a $\mathrm{CO}_{2}$ capture system using $\mathrm{CaO}$, Chemical Engineering Journal 147 (2009) 252-258.

[21] G. S. Grasa, J. C. Abanades, $\mathrm{CO}_{2}$ capture capacity of $\mathrm{CaO}$ in long series of carbonation/calcination cycles, Industrial \& Engineering Chemistry Research 45 (2006) 8846-8851.

[22] D. Bonaventura, R. Chacartegui, J. Valverde, J. Becerra, V. Verda, Carbon capture and utilization for sodium bicarbonate production assisted by solar thermal power, Energy Conversion and Management 149 (2017) 860-874.

[23] A. Gupta, C. D. Maranas, Managing demand uncertainty in supply chain planning, Computers \& Chemical Engineering 27 (2003) 1219-1227.

[24] R. Gärtner, G. Witkamp, Wet calcining of trona (sodium sesquicarbonate) and bicarbonate in a mixed solvent, Journal of Crystal Growth 237 (2002) 2199-2204.

[25] W. H. Bradley, H. P. Eugster, Geochemistry and paleolimnology of the trona deposits and associated authigenic minerals of the Green River Formation of Wyoming, Technical Report, United States Government Printing Office, Washington (United States), 1969.

[26] F. Suner, Beypazari trona deposits, PhD Dissertation, Istanbul Technical University, 1989.

[27] Y. Zhang, Geology of the Wucheng trona deposit in Henan, China, in: Sixth International Symposium on Salt, volume 1, 1985, pp. 67-73.

[28] H. W. Haynes Jr., Thermodynamic solution model for trona brines, AIChE Journal 49 (2003) 1883-1894.

[29] J. C. Abanades, E. J. Anthony, J. Wang, J. E. Oakey, Fluidized bed combustion systems integrating $\mathrm{CO}_{2}$ capture with $\mathrm{CaO}$, Environmental Science \& Technology 39 (2005) 2861-2866.

[30] S. Ebrahimi, C. Picioreanu, R. Kleerebezem, J. Heijnen, M. Van Loosdrecht, Ratebased modelling of $\mathrm{SO}_{2}$ absorption into aqueous $\mathrm{NaHCO} 3 / \mathrm{Na} 2 \mathrm{CO} 3$ solutions accompanied by the desorption of $\mathrm{SO}_{2}$, Chemical Engineering Science 58 (2003) 3589-3600.

[31] V. Nikulshina, N. Ayesa, M. Galvez, A. Steinfeld, Feasibility of Na-based thermochemical cycles for the capture of $\mathrm{CO}_{2}$ from air - Thermodynamic and thermogravimetric analyses, Chemical Engineering Journal 140 (2008) 62-70.

[32] Y. Li, C. Zhao, H. Chen, Q. Ren, L. Duan, CO $\mathrm{C}_{2}$ capture efficiency and energy requirement analysis of power plant using modified calcium-based sorbent looping cycle, Energy 36 (2011) 1590-1598. 
[33] B. J. McBride, M. J. Zehe, S. Gordon, NASA Glenn coefficients for calculating thermodynamic properties of individual species (2002).

[34] MathWorks Documentation, fmincon (2018). URL: https://www . mathworks. com/help/optim/ug/fmincon.html.

[35] K. Z. House, C. F. Harvey, M. J. Aziz, D. P. Schrag, The energy penalty of postcombustion $\mathrm{CO}_{2}$ capture \& storage and its implications for retrofitting the US installed base, Energy \& Environmental Science 2 (2009) 193-205.

[36] W. Dai, Process and reactor level simulations of calcium looping combustion, 2015.

[37] R. Carapellucci, D. Di Battista, R. Cipollone, The retrofitting of a coal-fired subcritical steam power plant for carbon dioxide capture: A comparison between MCFCbased active systems and conventional MEA, Energy Conversion and Management 194 (2019) 124-139.

[38] C. Ortiz, J. M. Valverde, R. Chacartegui, Energy consumption for $\mathrm{CO}_{2}$ capture by means of the calcium looping process: A comparative analysis using limestone, dolomite, and steel slag, Energy Technology 4 (2016) 1317-1327.

[39] L. M. Romeo, J. C. Abanades, J. M. Escosa, J. Paño, A. Giménez, A. SánchezBiezma, J. C. Ballesteros, Oxyfuel carbonation/calcination cycle for low cost $\mathrm{CO}_{2}$ capture in existing power plants, Energy Conversion and Management 49 (2008) 2809-2814.

[40] I. Vorrias, K. Atsonios, A. Nikolopoulos, N. Nikolopoulos, P. Grammelis, E. Kakaras, Calcium looping for $\mathrm{CO}_{2}$ capture from a lignite fired power plant, Fuel 113 (2013) 826-836.

[41] A. Doukelis, A. Koumanakos, Papapavlou ch. 380 mwe gross dry lignite pf power plant performance with integrated $\mathrm{CO}_{2}$ capture-mea base case solvent, report in CASTOR project, 2007.

[42] K. Annamalai, I. K. Puri, M. A. Jog, Advanced Thermodynamics Engineering, 1 ed., CRC Press, Florida, USA, 2011.

[43] M. N. C. Bannerman, Ideal Gas Model (2018). URL: http://simcem.com/\#volume-explicit-models.

[44] J. Smith, H. Van Ness, M. Abbott, Introduction to Chemical Engineering Thermodynamics, 6 ed., McGraw-Hill, New York, USA, 2001. 